UNITED STATES DEPARTMENT OF THE INTERIOR

J. A. Krug, Secretary

GEOLOGICAL SURVEY

W. E. Wrather, Director

Bulletin 954-D

OPTICAL CALCITE DEPOSITS

OF THE

REPUBLIC OF MEXICO

BY

CARL FRIES, JR.

Prepared in cooperation with the

COMITE DIRECTIVO PARA LA INVESTIGACION

DE LOS RECURSOS MINERALES DE MEXICO

under the auspices of

INTERDEPARTMENTAL COMMITTEE ON SCIENTIFIC AND

CULTURAL COOPERATION, DEPARTMENT OF STATE

Geologic Investigations in the American Republics, 1946

(Pages 113-179)

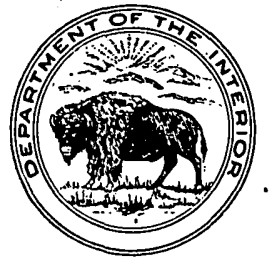

UNITED STATES

GOVERNMENT PRINTING OFFICE

WASHINGTON : 1948

For sale by the Superintendent of Documents, U. S. Government Printing Office, Washington 25, D. C. Price 20 cents 



\section{CONTENTS}

Page

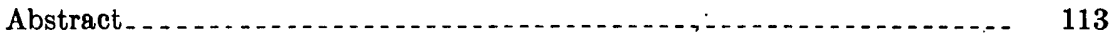

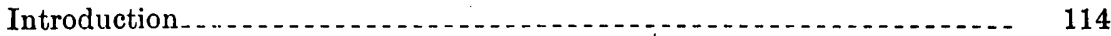

Distribution and accessibility of deposits. . .

Field work and acknowledgments_._.

History of exploration and mining .

Varieties and properties of the mineral calcite.......... 119

Common varieties based on crystallization................ 119

Properties of calcite crystals...

Forms and habits................ 120

Twins and twinning lamellae............................ 123

Physical, optical, and chemical properties................ 128

Optical calcite

Terms applied, uses, and specifications . 130

Common defects and their recognition.....

Consumption, markets, and prices_.

Geologic character of deposits............... 137

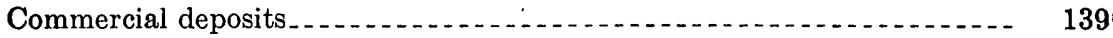

Shape and size........

Structures favorable to occurrence of optical calcite........... 140

Factors affecting quality of calcite........ 141

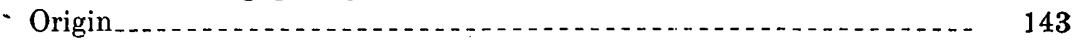

Methods of mining, cleaving, and selecting usable calcite........ 145

Suggestions for prospecting . . . . . . .

Marketing of Mexican optical calcite

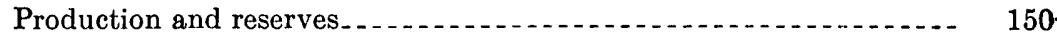

Mines and districts examined................... 153

La Fe mine, Rodeo, Durango (1) . . . . . . . . . . .

Areponápuchic district, Chihuahua (2)

El Porvenir deposit.............. 156

La Aurora deposit. .............. 157

La Flor de Esperanza deposit. 158

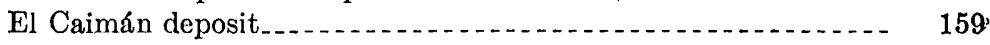

Deposits along the La Perla vein.

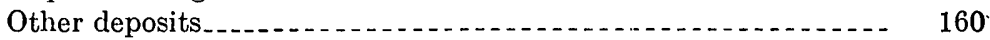

El Murciélago district, Manuel Benavides, Chihuahua (3) ........ 160

Bacadéhuachic district, Sonora (4)

Pito Real district, Chihuahua (5) ................

El Parrón district, Manuel Benavides, Chihuahua (6) _.......... 165

Monterde district; Chihuahua (7) _....................... 165

San Isidro district, Durango (8)

El Cristal mine, Cumpas, Sonora (9)

Oputo district, Sonora (10)

Chínipas district, Chihuahua (11)

El Caliche mine, Mazocahui, Sonora (12)

La Esmeralda mine, Guagüeybo, Chihuahua (13)

Mapimi district, Durango (14 and 15)

District east of Esqueda, Sonora (16) _...

Arizpe district, Sonora (17) $\ldots \ldots$ 
Mines and districts examined-Continued Page

Tarahuacáchic district, Sonora (18) _..................... 173

Guásabas district, Sonora (19)

Chuhuichupa district, Chihuahua (20)

Sahuaripa district, Sonora (21) _......

District south of La Mula, Chihuahua (22) $\ldots \ldots \ldots$

District south of Manuel Benavides, Chihuahua (23) ............. 174

District east of Manuel Benavides, Chihuahua (24) . . . . . . . . 174

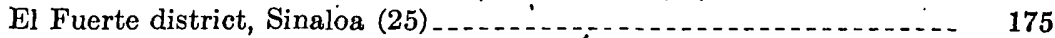

San Javier district, Sinaloa (26) _...

Pitayita district, Sinaloa (27)

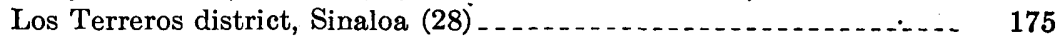

District south of Antonio Amaro, Durango (29) _.............. 176

District east of Antonio Amaro, Durango (30)

Ochoa district, Durango (31)

Index

\section{ILLUSTRATIONS}

Plate 23. Index map of Mexico showing location of optical calcite districts examined and reiative importance of productive districts . . . . . . . . . .

24. Various vein structures in which commercial calcite occurs. . In pocket

25. Map and sections of the El Porvenir and El Caimán calcite deposits... . . . In pocket

26. Map and sections of the La Aurora calcite deposit......... In pocket

27. Sketch showing location of calcite veins mined near Areponápuchic, Chihuahua........................ In pocket

28. Sketch map and section of the El Murciélago calcite district, southeast of Manuel Benavides, Chihuahua ............ In pocket

29. Map and section of the La Esmeralda calcite deposit, near Guagüeybo, Chihuahua ...... In pocket

30. Geologic map and section of the La Fe calcite deposit, near

Rodeo, Durango . . . . .

31. Map and sections of the La Flor de Esperanza calcite deposit_ In pocket

32. Map and section of the La Perla calcite deposit.......... In pocket

Figure 8. Drawings of calcite crystal forms: rhombohedrons......... 121

9. Drawings of calcite. crystal forms: ${ }^{\circ}$ scalenohedrons and base _._ 122

10. Drawings of calcite crystal forms: first- and second-order prisms and second-order pyramid..................... 124

11. Drawings of the four types of calcite twin crystals $\ldots \ldots \ldots \ldots$

12. Drawings of a twin crystal typical of those found near Areponá-

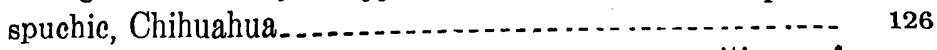

13. Drawings of cleavage rhombohedrons showing positions of twinning planes and some defects in optical calcite..........

14. Drawings of cuts made from smallest cleavage rhomobohedron 127 accepted for suboptical use, and of a common crystal habit

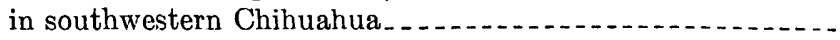

15. Drawings of a plate of calcite typical of those in the La Fe deposit near Rodeo, Durango..................................... 


\title{
OPTICAL CALCITE DEPOSITS OF THE REPUBLIC OF MEXICO
}

\author{
By Carl Fries, Jr.
}

\section{ABSTRACT}

Many small deposits of optical calcite (Iceland spar) were discovered in the States of Chihuahua, Durango, Sonora, and Sinaloa from early in 1942 to late in 1944. Exploration that began in Sonora led to the discovery of commercial deposits in the eastern part of that State, and subsequently other deposits were found and mined in southwestern and northeastern Chihuahua and in western and central Durango. The largest deposits can be reached by foot or by horse in from 1 to 3 hours from the nearest truck roads, but some of the small deposits are 1 to 3 days by horse from the nearest roads.

Optical calcite is obtained from well-crystallized single crystals of pure calcite, calcium carbonate $\left(\mathrm{CaCO}_{3}\right)$, and in this report it is classified on the basis of clarity into two categories: (1) The material of greatest purity and clarity, generally known as Iceland spar, is called high-grade optical calcite; and (2) material somewhat less clear but nevertheless used in optics is called suboptical calcite. There is no generally accepted precise line of division between the two types.

High-grade optical calcite is colorless, perfectly clear-that is, without clouds, cavities, or microscopic inclusions-free from twinning lamellae, free from cleavage fractures, and large enough to yield cleavage rhombohedrons at least 3.5 centimeters long, 1.8 centimeters wide, and 1.8 centimeters thick. ${ }^{1}$ It is used almost entirely in the manufacture of polarizing prisms, such as those in petrographic microscopes. dichroscopes, polariscopes, saccharimeters, colorimeters, and photometers. World consumption in normal times probably seldom exceeded 500 pounds a year.

Suboptical calcite must meet all the specifications just given except that it may have faint color and contain faint clouds, and cleavage rhombohedrons must measure at least 2.86 centimeters in each of the three dimensions. It has been used principally in the manufacture of optical ring gun sights, and small quantities are purchased by mineral dealers and collectors, colleges, museums, and commercial chemical laboratories. Before 1943 there was little demand for suboptical calcite, but consumption in 1943 and 1944 rose to the rate of about 10,000 pounds a year. Consumption since 1944 has been much smaller.

Virtually all optical calcite is found in deposits containing no minerals but calcite, and it is found only where such deposits have cavities into which crystals were free to grow without interference. Favorable structures are fissures, open faults, lenticular or pipelike zones of breccia, and irregular openings formed by flowage in lavas. All commercial deposits are in areas of geologically recent yolcanic activity, and accordingly most of them are in volcanic rocks of Tertiary or Quaternary age. They were formed apparently within 600 meters of the surface-some possibly within 20 or 30 meters-in openings containing hot carbonated waters. The deposits are mere pockets, most of them too far apart to permit extensive underground mining, and consequently they rarely can be

1 The metric system is used in this report for all measures except weights, which are given in pounds because all purchases of calcite have been made in United States currency at specified prices per pound. 
mined profitably to a depth exceeding 30 meters. The quality of the calcite is not affected by weathering, and if no usable material is found at or within a meter of the surface, deeper exploration is likely to be unprofitable.

The total production of optical calcite in Mexico up to November 15, 1944, was roughly 11,750 pounds, of which about 160 pounds was of high-grade optical quality. An estimated 1,700 pounds of usable material was on hand after the demand for suboptical calcite was curtailed; this material probably contained a few pounds of high-grade optical calcite. Seventy-five percent of the production came from two mines, and the rest came from more than 100 small mines, each of which yielded from 1 to 500 pounds, although few yielded more than 200 pounds.

Reserves cannot be calculated as in metalliferous deposits, because of the highly pockety nature of optical calcite deposits. To maintain a suboptical calcite production of 1,000 pounds a month over a period of more than a year, a price of about $\$ 8$ per usable pound would have to be paid, and to obtain a continued production of 1,500 pounds a month, the price would probably have to be at least $\$ 12$ per usable pound. It is questionable whether there could be a uniformly sustained production of high-grade optical calcite alone even at a price of $\$ 100$ a pound, although a few pounds might be produced from time to time.

\section{INTRODUCTION}

\section{DISTRIBUTION AND ACCESSIBILITY OF DEPOSITS}

Deposits of optical calcite (Iceland spar) had been mined in Mexico, up to the end of November 1944, in the States of Sonora, Chihuahua, and Durango, and although other deposits occur and had been prospected in several other States, notably Sinaloa, desultory exploration had not led to the discovery of any of commercial value. . (See pl. 23). The calcite of highest quality was found in Chihuahua, in deposits southeast of Manuel Benavides (3 and 6) ${ }^{2}$ in the eastern part of the State, and in deposits near Areponápuchic (2 and 5 ) in the southwestern part of the State. Other deposits that yielded calcite of high quality are near Cumpas (9) and Mazocahui (12) in eastern Sonora, and near San Isidro (8) in western Durango. Those that yielded the largest amounts of usable calcite, though not of such high quality, are near Rodeo (1), in central Durango; near Arepoṇápuchic (2) and Manuel Benavides (3), in Chihuahua; and near Bacadéhauchic (4), in eastern Sonora.

The deposits in eastern sonora, such as thoso near Cumpas (9); Oputo (10), Guásabas (19), and Bacadéhuachic (4), can be reached by truck from Nacozari, the end of a short railroad line south from Agua Prieta, at the border. These deposits are half an hour to an hour by foot from the road, except the Bacadéhuachic deposits, which require about 8 hours by horse from the end of the road at Granados. Except after heavy rains in July and August, these deposits and all others in eastern Sonora are accessible throughout the year.

\footnotetext{
2 The numbers in parentheses after the names of districts and mines refer to the districts numbered on the map in plate 23.
} 
The Manuel Benavides (3 and 6) districts in northeastern Chihuahua can be reached by truck from Chihuahua City or from Ojinaga at the United States border. The least accessible deposits in those districts are less than an hour by foot from the road. Some of the other deposits in northeastern Chihuahua, such as those south of La Mula (22) and south of Manuel Benavides (23), are 2 to 5 hours by horse from the nearest roads. The deposits in southwestern Chihuahua are reached by truck from Chihuahua City or from Creel, the end of the railroad from Chihuahua or Ciudad Juárez. The roads are passable except after heavy rains in the summer months.

The deposits north of Mapimí (14 and 15), in northeastern Durango, can be reached by truck from Mapimí, the nearest railroad station, or directly from the large city and communications center of Torreon, Coahuila. The La Fe mine (1) in central Durango is 3 hours by horse southwest of Rodeo, a town along the gravel highway leading north from Durango City. The San Isidro (8) deposits, in western Durango, are best reached from Cosalá, Sinaloa, the end of poor dirt roads from Culiacán and from Santa Cruz, which is the nearest station on the railroad. These and other deposits in the region are a day to a day and a half by horse from Cosalá. During the rainy season, which lasts throughout the summer, the rivers are frequently too high to permit travel by automobile. Deposits in eastern Durango can be reached from Durango City throughout the year. Those in northcentral Sinaloa are reached from Culiacán, by way of Badiraguato, when the roads are dry, as they generally are during the winter and spring.

\section{FIELD WORK AND ACKNOWLEDGMENTS}

This study was undertaken as a part of the United States Geological Survey's program of cooperation with the American Republics, under the sponsorship of the Interdepartmental Committee on Scientific and Cultural Cooperation, United States Department of State. In Mexico this program is being carried on by the Comité Directivo para la Investigación de los Recursos Minerales de México, under the auspices of the Secretaría de la Economía Nacional, and engineers and geologists of the Comité, the Dirección de Minas, and the Instituto de Geología have been working with geologists of the United States Geological Survey. As all the Mexican geologists and engineers engaged in collaborative work were occupied with other assignments while the calcite studies were being made, the writer worked alone, although Ing. Reinaldo Guiza, Jr., of the Comité, who was engaged in other studies in Durango, accompanied the writer in the examination of three small nonproductive deposits in eastern Durango. 
Field work was begun by John H. Wiese, of the Geological Survey, who examined several deposits in Sonora in December 1943. Because of Mr. Wiese's illness the writer took over his work in February 1944 and continued to examine calcite deposits until the following December, when all mining had ceased. The urgent need to visit all the known occurrences as soon as possible, so that production might be brought up quickly to a satisfactory level, precluded detailed studies and maps until after August 1944. At that time the writer again began to visit the producing deposits with the object of making detailed studies and maps, but because of the relative inaccessibility of many of the deposits he was able to map only a few before mining ceased. Maps were made, however, of the most extensively mined and most productive deposits. Kenneth Segerstrom, Topographic Engineer of the United States Geological Survey, helped to prepare the map of the La Fe deposit (1), near Rodeo, Durango.

As the rock names used in this report are based on field identifications only, not all of them are precise. At the time of this writing no laboratory studies have been made of the calcite crystals collected, but such studies are planned after more urgent work has been finished. The drawings in figures 8 to 15 are not exact reproductions of particular crystals but are generalized to illustrate certain features of calcite crystals and to show some of the habits of crystals commonly found in the important districts.

Although the writer was assisted during field work by more persons than he can name, he is particularly indebted to Ben F. Williams, of Douglas, Ariz., for information and assistance throughout this period and for all production data. He also acknowledges the valuable aid of Martín B. Nesbitt and C. R. King, of Chihuahua City, during field work in Chihuahua, and of Hugo P. Keller, Jr., of New York City, during field examinations in central and northeastern Durango. Valuable assistance in making contacts with people interested in calcite was given by Robert Peyton, United States Vice Consul in Chihuahua City. The writer learned to cleave and select calcite under the able direction of O. A. Reese, of Colorado Springs, Colo. John H. Wiese, of the Geological Survey, and C. E. Pouliot, of the Foreign Economic Administration, freely gave information on the deposits examined by them. Thanks are especially offered to the mine owners and prospectors in the many districts examined, without whose help this study could not have been made. Many of them are cited by name under the descriptions of the individual mines.

In the preparation of the report, the assistance of David Gallagher, John Van N. Dorr, 2d, and Norah D. Stearns, of the Geological Survey, and of William F. Foshag, of the Smithsonian Institution, in 
critical and constructive review of the manuscript and drawings was of great value and is particularly appreciated.

\section{HISTORY OF EXPLORATION AND MINING}

The first search for optical calcite in Mexico, so far as the writer knows, began several years after World War I. Small transparent calcite crystals were found in a cavity or cave near Tónichi, Sonora, and were sent to Hugo Miller, an assayer in Nogales, Ariz. Examination of the crystals by the Bausch \& Lomb Optical Co., of Rochester, N. Y., showed them to be unsuitable for optical use, and no further work was done on the deposit. ' In 1941, Dr. E. M. Stanton, who had been operating an optical calcite mine near Taos, N. Mex., and was familiar with methods of mining and selection, began a search for piezoelectric quartz and optical calcite in eastern Sonora and in Sinaloa, with the aid and under the sponsorship of Ben. F. Williams, of Douglas, Ariz. As a result of their investigations the deposits near Cumpas (9) and Mazoçahui (12) were discovered and opened in 1942.

In the summer of 1943 Francisco Batista, of Areponápuchic, Chihuahua, who had recently learned from an acquaintance that calcite crystals had a high commercial value, discovered and explored a deposit near his home. While inquiring about a market for the material, he contacted C. R. King, of Chihuahua City, who sought markets in the United States. It happened that the Polaroid Corporation of Cambridge, Mass., was then actively searching for optical calcite of a quality considerably lower than that hitherto used, for the manufacture of a new product developed by one of its staff. Upon learning of the Areponápuchic deposit through Mr. King, the Polaroid Corp. arranged that Dr. Stanton, with whom it had been in contact, examine the deposit with Mr. King. Accordingly, the deposit was examined and after a small amount of mining was found to be commercial. As a result, Sr. Batista and his associates, Carlos Silva, of Urique, and Martín Nesbitt, of Chihuahua City, began actively to explore and mine this and other deposits in the region. This group of men, with other associates, subsequently produced virtually all the calcite obtained from southwestern Chihuahua.

While Mr. King investigated other deposits in southwestern Chihuahua during the fall of 1943, Dr. Stanton examined some deposits that had been brought to the attention of Mr. Williams, near Chuhuichupa (20) in the western part of Chihuahua. In November 1943, while on a flight to that region in his private plane with a friend, Dr. Stanton disappeared and was presumed to have crashed, whereupon. the Polaroid Corp. through Mr. Williams made arrangements with Carl Farnsworth, the discoverer of the Chuhuichupa deposits, to 
continue exploration and mining. The plane and remains were not found until August of the following year, some 9 months later. In December 1943, however, when it had become evident that Dr. Stanton was lost, the Polaroid Corp. arranged to procure all the calcite from Mexico through Mr. Williams, who had been sponsoring Dr. Stanton. Mr. King then began to select and purchase calcite in the field in Chihuahua for Mr. Williams.

At the time of Dr. Stanton's disappearance the United States Navy Department, for whom the calcite product was being made by the Polaroid Corp., requested that the Geological Survey and the Foreign Economic Administration aid in the field work. John $\mathrm{H}$. Wiese, of the Geological Survey, 'begąn investigating the Sonora deposits in December 1943, and L. W. Storm of the office of the Foreign Economic Administration in Mexico City began investigating the deposits then known in Chihuahua. After Mr. Storm's return to Mexias City in December 1943, the Foreign Economic Administration prepared a circular explaining the specifications and market for optical calcite and sent it to persons interested in calcite in different parts of Mexico. In February 1944, C. E. Pouliot continued the work begun by Mr. Storm, investigating deposits in Sonora and Sinaloa, and in the same month the writer continued the work begun by Mr. Wiese, with the object of examining all the known deposits not already investigated. On several trips the writer was accompanied by $O$. A. Reese, who had gained valuable experience in cleaving and selecting calcite for the Polaroid Corp. at its deposits in Montana. Mr. Reese instructed the owners of the deposits visited, as well as the writer, how to cleave and select usable calcite.

As a result of promotion by Mr. Williams early in 1944, the Oputo (10) deposits were explored by Antonio E. Samaniego, of Oputo; the Bacadéhauchic (4) deposits were opened by Astolfo Valenzuela, of Bacadéhnuchic; and the San Isidro (8) deposits were explored by Severo Robles, of San Isidro, Durango, and Angel N. Zazueta, of Cosala, Sinaloa. As a result of stimulation both by word and by circulars issued by the office of the Foreign Economic Administration in Mexico City, the El Murciélago (3) and El Parrón (6) districts were explored by Jesús and Pedro Rohana, of Ojinaga, Chihuahua, and Jesus Gandera Parme, of Chihunhur City; the Mapimí (14 and 15) deposits were found and mined under the direction of Arnulro Giwrse and Angel Tavera, of Torreón, Coahuila; and the Rodeo (1) deposit was explored by Adolfo Torrecillas, of El Salto, Durango. C. R. King and L, V. Blum, of Monterde, stimulated the opening of the deposits in the Chinipas district (11). At all the deposits visited by the representatives of the Geological Survey and the Foreign Economic 
Administration, the owners were instructed how to mine, cleave, and select usable calcite, and brief studies were made of the occurrence of the mineral.

All calcite mining had come to an end by November 11, 1944, as the. demand for all but the highest quality of calcite had been sharply curtailed, but activity at many deposits where mining had not been found profitable had ended long before that. The Mazocahui (12) deposits were not mined after the summer of 1943 , and there was no further activity at Cumpas (9) after March 1944. Activity at the Mapimí (14 and 15) deposits ended after March 1944, and no further work was done at Oputo (10) after August of the same year. Mining ceased at Bacadéhuachic (4) in August 1944 and at San Isidro (8) in September 1944. All calcite mining was stopped in southwestern Chihuahua late in October 1944, because of the imminent termination of the procurement program, but some of the mines in that region had been shut down even earlier. Calcite mining was halted in the northeastern Chihuahua districts (3 and 6) in November 1944, and La Fe mine (1) in central Durango was closed down on the 11th of the same month.

\section{VARIETIES AND PROPERTIES OF THE MINERAL CALCITE}

\section{COMMON VARIETIES BASED ON CRYSTALLIZATION}

Calcite, calcium carbonate $\left(\mathrm{CaCO}_{3}\right)$, is one of the most widely distributed of all the minerals in the surface of the earth: there are few areas as large as a square kilometer where it is not found in one or more of its various forms. It occurs (1) in compact and earthy masses of small grains varying in size from those barely visible under a microscope to those easily seen by the naked eye, (2) in compact masses of fibers and lamellae, and (3) in single crystals of widely varying habit.

The compact varieties of calcite, as given above, are not suitable for optical use, although they are the most widely distributed and the best known of all the common varieties. Limestone and its metamorphic equivalent marble, which form many thousands of cubic kilometers of the earth's thin outer layer, consist almost entirely of calcite. The whitish deposits and cementing material so common in the weathered surface zone in the semiarid western part of the United States and central Mexico, locally called caliche, consist in large part of calcite. Locally, in and near hot springs and streams, calcite is deposited as travertine, sinter, and tufa. By evaporation of water dripping from the roofs of caverns and caves in and near lime-bearing rocks, calcite is deposited as elongate stalactites, which 
hang from the roof, and elongate or moundlike stalagmites projecting from the floor. Some of the material in the large travertine and stalagmitic deposits is sometimes called calcite "alabaster" or calcite "onyx" (Mexican onyx). ${ }^{3}$

All optical calcite, with which this report is concerned exclusively, is obtained from large well-formed crystals, occurring either singly or in clusters, with almost any outward shape. Such crystals can form in cavities or openings of any kind, and they may occur in any kind of rock, either sedimentary, metamorphic, or igneous. Although openings in rocks are multitudinous in kind and origin, some of the most common and important types in which crystals of optical calcite occur are: (1) fissures and irregular openings due to faulting, folding, or contraction, (2) caverns formed in lavas by flowage, (3) cavities and vugs in intrusive and extrusive igneous rocks, and (4) caverns in limestone and other soluble rocks.

\section{PROPERTIES OF CALCITE CRYSTALS}

In order to present an adequate description of the crystallography of calcite, the author must assume that the reader is familiar with the science of crystals, although he realizes that this subject may be new and unfamiliar to many readers. In general it is not necessary for the miner or producer of optical calcite to know the principles involved in the discussions that follow, which, together with the illustrations, will nevertheless aid the producer to cleave and select usable calcite. Those not familiar with the subject who find that a background is desirable are referred to any standard textbook treating of crystals, such as Dana's Textbook of Mineralogy, published in 1932 by. John Wiley \& Sons, Inc., of New York.

\section{FORMS AND HABITS}

Calcite crystallizes in the rhombohedral division of the hexagonal crystal system. Although its symmetry, like that of quartz, is in some respects sixfold, essentially it is only threefold. Generally tho symmetry is expressed characteristically by two common forms, the rhombohedron (fig. 8) and the scalenohedron (fig. 9). The rhombohodron is a solid bounded by six faces, each a rhomb, as illustrated by $A$ in figure 8 , and the scalenohedron is a solid bounded by twelvo faces, each a scalene triangle, as shown by $A$ in figure 9 . A characteristic feature of the scalenohedron is the arrangement of its faces in pairs, such that tho ang to botwoon the facos of ono nair is different from the angle between those of the next pair, as illustrated by $B, D$, and $F$ in figure 9 . There are various scalenohodrons, depending upon

\& For a more complete description see Ford, William $E$., Dana's textbook of mincralpgy, 4th ed., pp. 513516, New York, John Wiley \& Sons, Inc., 1932. 


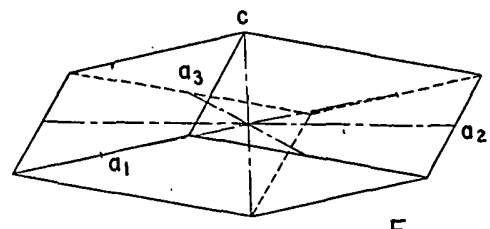

E.
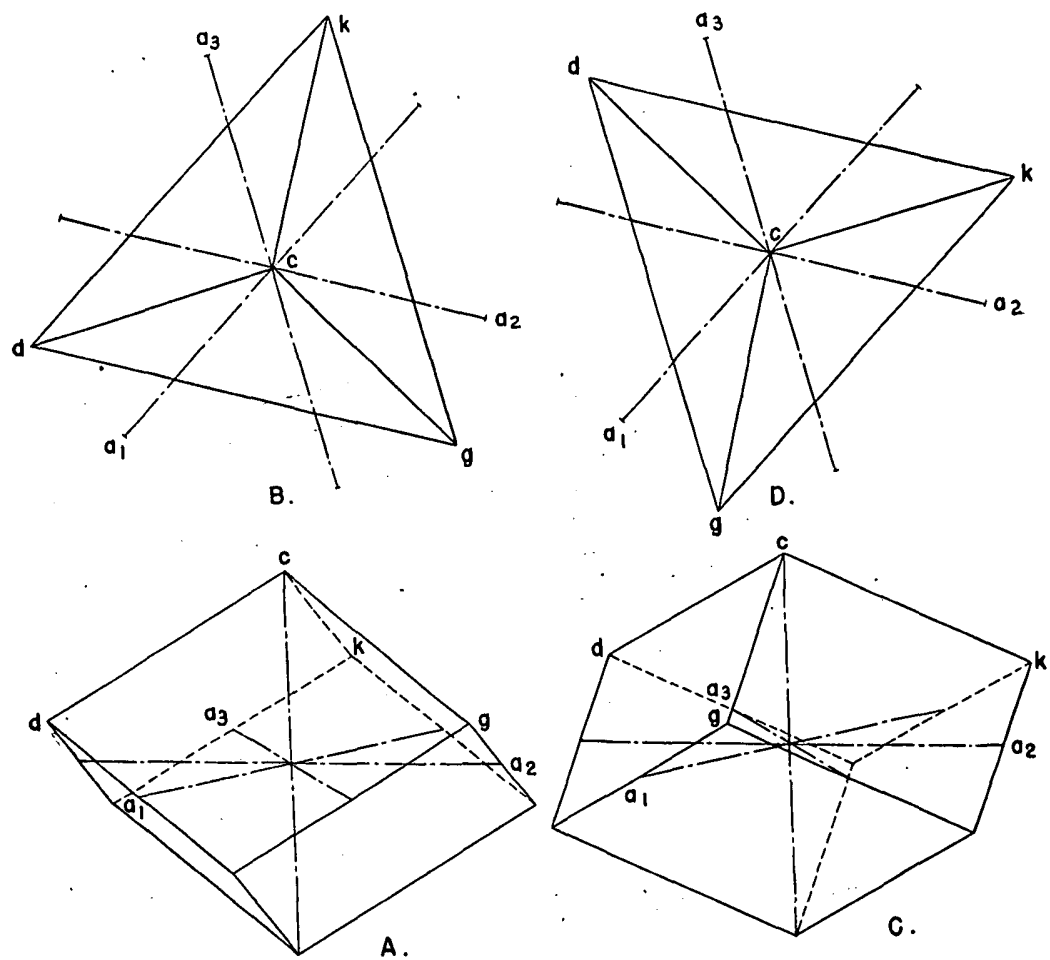

Figure 8.-Drawings of calcite crystal forms: rhombohedrons. $A$, positive unit or cleavage rhombohedron $r(1011) ; B$, top view of $A$ above plane through $d, g$, and $k$, showing outline of basal cut; $C$, negative unit rhombohedron $p(01 \overline{1} 1) ; D$, top view of $C$ above plane through $d, g$, and $k$, showing outline of basal cut; $E$, negative unit rhombohedron $e(01 \overline{1} 2)$, to whose faces the most common type of twinning lamellae in calcite are parallel.

the difference in the angles between the alternate pairs of faces and upon the inclination of the faces to the vertical (c) axis (compare fig. $9 B$ with fig. $14 F$ ). The scalenohedral form distinguishes calcite crystals from six-sided quartz crystals, on which the angles between all the faces are equal.

Both the rhombohedron and the scalenohedron have negative as well as positive forms (compare fig. $8 A$ with fig. $8 C$, and fig. $9 A$ with fig. $9 C$ ). The relation of the negative form may be obtained by rotating the positive form on the vertical axis $60^{\circ}$ in either direction, without changing the position of the horizontal axes. 


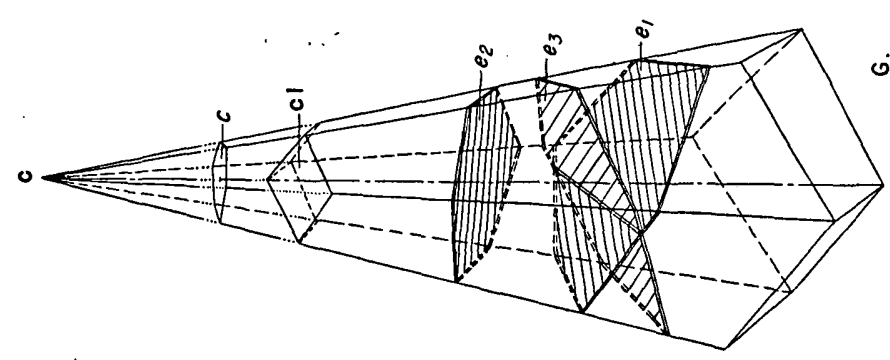

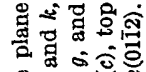

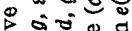
के क 论 菏 要

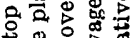
m $\because \infty \mathrm{i}$ 售记 겅

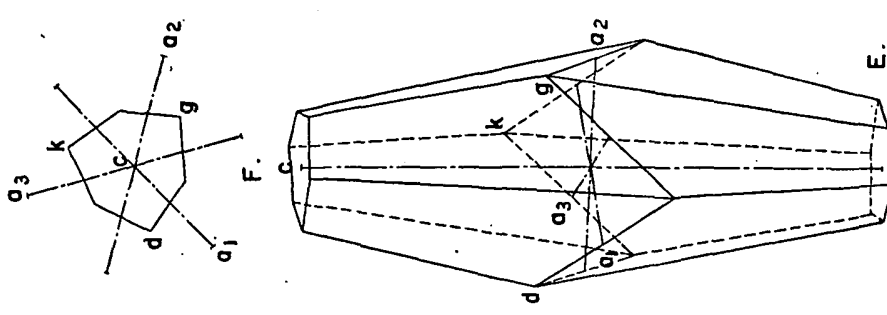

然语

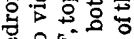

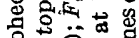

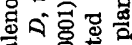
边

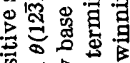

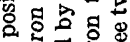
४ 实焉 \&

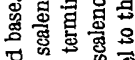
\&
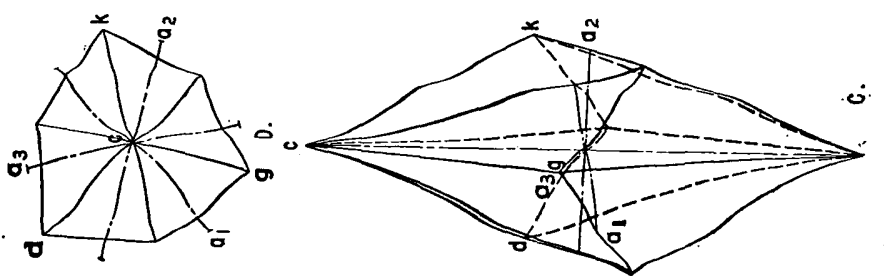

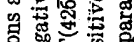
逮

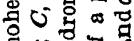

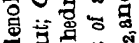

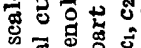

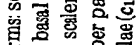
눙 용

可氙营心

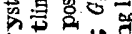

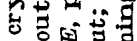

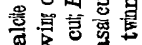
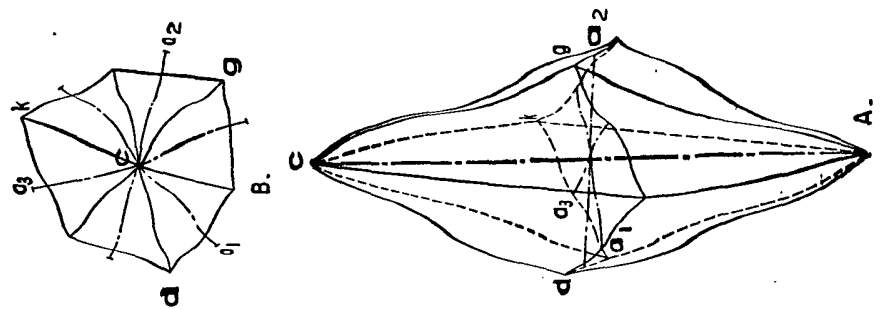

ฮั

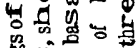
造它可

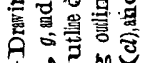
1000

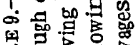
语

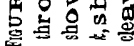


In some of the calcite districts a form commonly present is the base (fig. $9 E$ ), which on a complete crystal consists of only two faces, the top and bottom terminations. In southwestern Chihuahua the upper base is well developed on the crystals in most of the deposits, as on crystal $E$ in figure 14, and in the La Fe deposit in central Durango the upper and lower terminations, though actually only simulating the base, are virtually the only natural faces present, as shown in figure 15. A form not common in deposits examined in Mexico is the prism, a form consisting of six vertical faces, as shown on crystal $D$ in figure 10 . The prism may be of the first or second order, depending upon the relation of the faces to the horizontal axes (fig. 10A). The relation of the first- to the second-order prism may be obtained by rotating the crystal about the vertical axis $30^{\circ}$ in either direction, without changing the position of the horizontal axes. Two other forms, the thirdorder prism and the second-order pyramid, are very rare on calcite and consequently are unimportant.

\section{TWINS AND TWINNING LAMELLAE}

Some calcite crystals develop as twins, composed of two like parts joined along some special plane common to both individuals. The relation of one part of the twin to the other is one that might be obtained by rotating it $180^{\circ}$ on this special plane, which is called a twinning plane. This relation is illustrated by the twin crystals in figure 11, where it is most clearly shown by twin $A$. Four types of twinning plane, each of which may be referred to a simple crystal form, occur in calcite. The twinning plane may be parallel to: (1) the base $c$ (0001), (2) the positive unit rhombohedron $r$ (10 $\overline{1} 1)$, (3) a special negative rhombohedron $f(02 \overline{2} 1)$, or (4) the obtuse negative rhombohedron $e$ (0112). In the calcite deposits examined in Mexico no twins of type 1 were found, although they are abundant in some other parts of the world, nor were any seen of type 2, which are rare generally. Twins of type 3 are common in some of the Mexican deposits, although they are rare elsewhere, and those of type 4 are abundant in Mexico as elsewhere.

The most simple type of twin is that in which the base, the form $c$ (0001), serves as the twinning plane, as in twin $A$ in figure 11. Another simple type is that in which the twinning plane is parallel to a face of the positive unit rhombodehron, form $r$ (1011), such as that illustrated by $C$ in figure 11. In this twin the angle between the vertical (c) axes of the two parts is $904^{3 /}$. The third type, illustrated by $E$ in figure 11, is one in which the twinning plane is parallel to a face of a special negative rhombohedron, the form $f(02 \overline{2} 1)$. Although these twins are rare generally, they yielded most of the usable calcite obtained from the Bacadéhuachic (4) deposits in Sonora, and from 

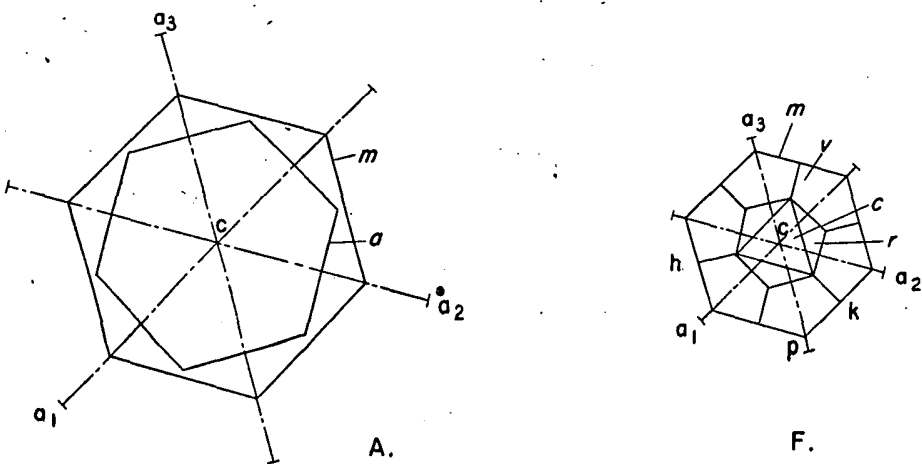

F.
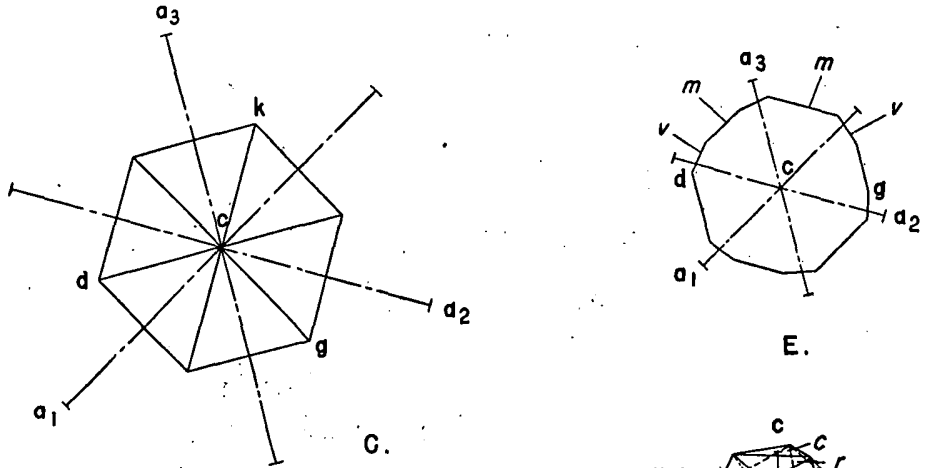

E.
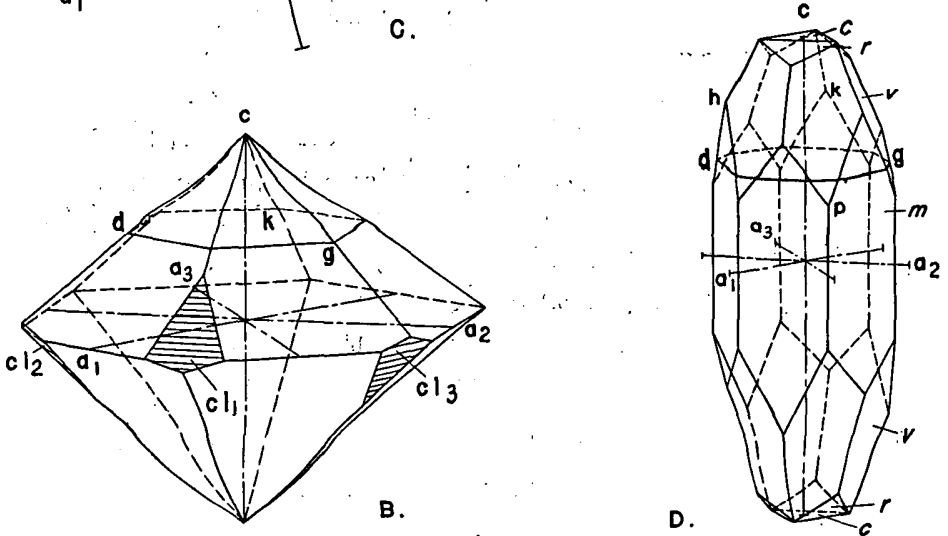

FlaUre 10.-Drawings of calcite crystal forms: first- and second-order prisms and second-order pyramid $A$, top view or horizontal section of prisms of first order $m(10 \overline{1} 0)$ and second order $a(1 \overline{1} 20)$; $B$, second-order pyramid $(11 \overline{2} 1)$, showing the three cleavages $\left(c l_{1}, c l_{3}\right.$, and $\left.c l_{3}\right) ; C$, top view of $B$ above plane dgk, showing outline of basal cut; $D$, crystal with first-order prism $(m)$, positive scalenohedron $(v)$, positive unit rhombohedron (r), or cleavage, and base (c); $E$, horizontal section of $D$ through $d g ; F$, top view of $D$ normal to c axis.

the Guagüeybo deposit (13) in southwestern Chihuahua. The fourth type of twin, $G$ in figure 11 , is one in which the twinning plane is parallel to a face of the obtuse negative rhombohedron, form $e$ (0112). In this type the angle between the vertical axes of the two individuals is $12712^{\circ}$. Such a twin can be produced artificially by pressing firmly 


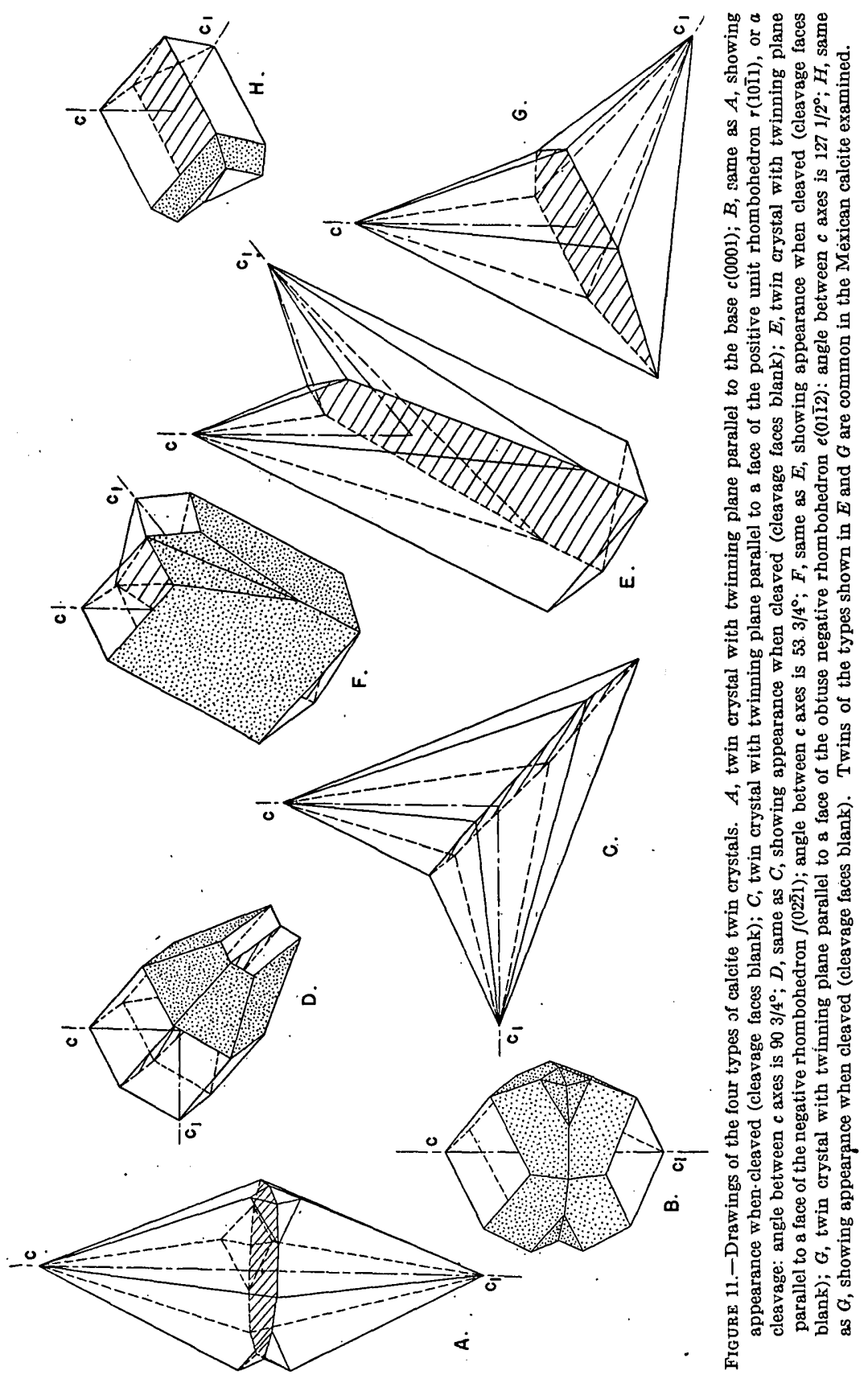


on the obtuse edge of a small cleavage rhombohedron. The twin crystal in figure 12, typical of twins in the Areponápuchic (2) district in southwestern Chihuahua, is of this type, although it has an uncommon habit.

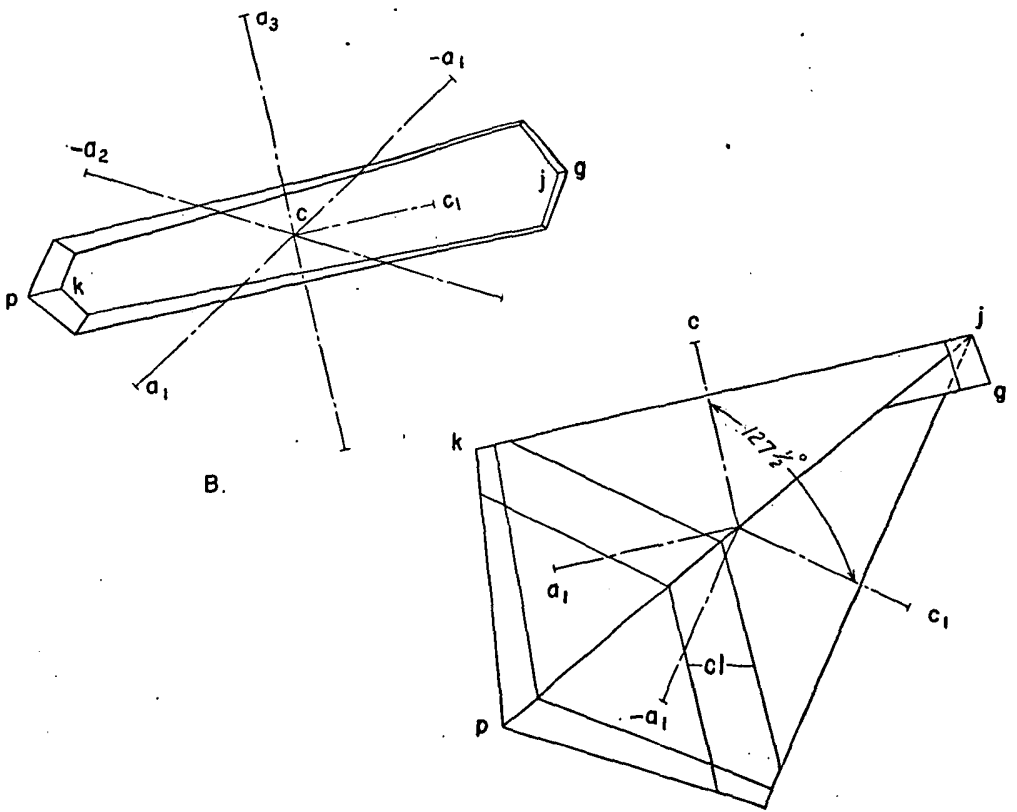

c.
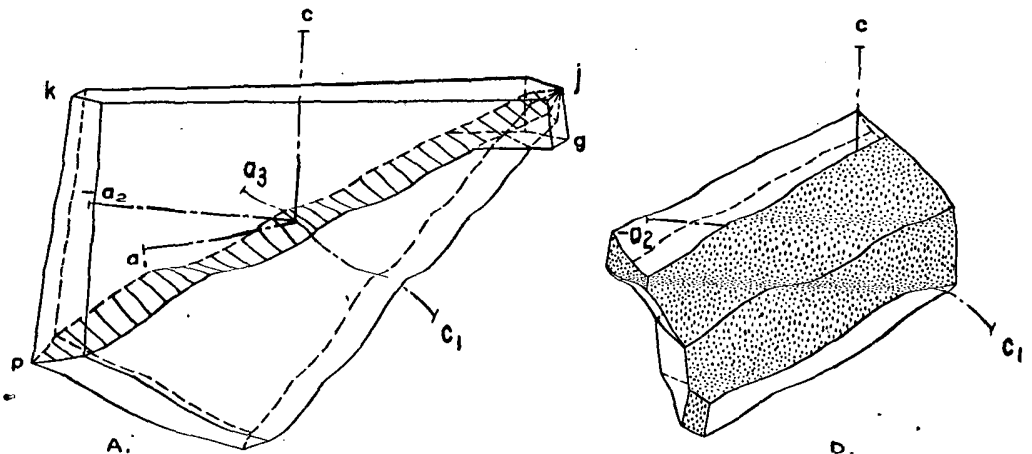

Froure 12.-Drawings of a twin crystal typical of those found near Areponápuchic, Chihuahula. $A$, clino. graphic projection of twin; $B$, top view of upper part of twin; $C$, front view normal to plane formed by crystal axes $\mathrm{c}$ and $\mathrm{c}$, showing trace of cleavage $(\mathrm{cl}) ; D$, same as $A$, showing appearance when cleaved (cleavage faces blank). Twinning plane is parallel to a face of the form $e$ (01ī2), as in crystal $G$ in figure 11 .

Twinning may occur in calcite in still another manner: instead of the twin consisting of two equal and like parts joined along a special plane common to both, one of the parts may be only a thin layer within the other, as shown in figure 13. Such a layer is called a 


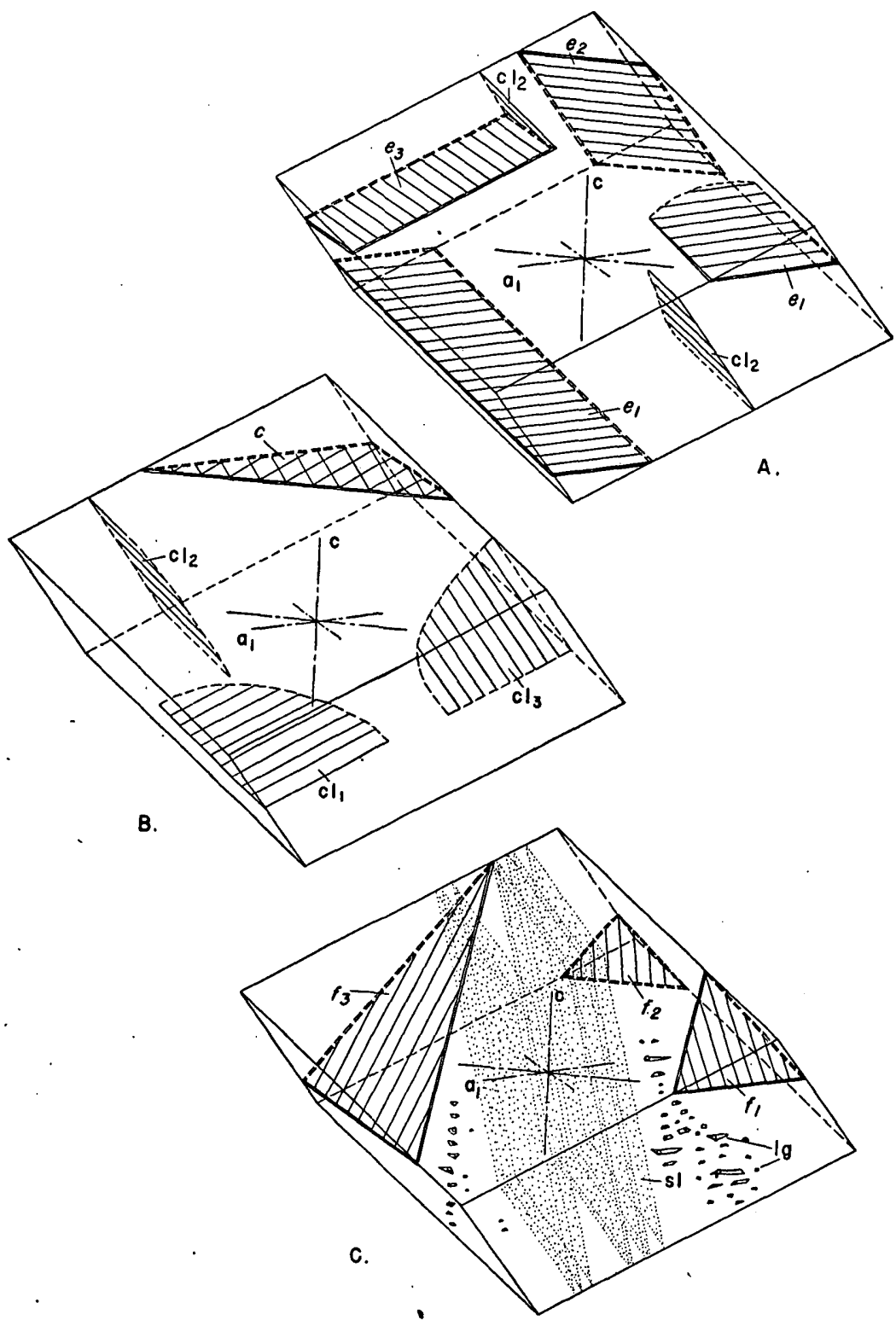

Froure 13.-Drawings of cleavage rhombohedrons showing positions of twinning planes and some defects in optical calcite. $A$, cleavage rhombohedron showing twinning lamellae $\left(e_{1}, e_{2}\right.$, and $\left.e_{3}\right)$ parallel to the three possible twinning planes of the obtuse negativ $\theta$ rhombohedron $e(01 \overrightarrow{1} 2)$, and two incipient cleavage fractures $\left(c l_{3}\right) ; B$, cleavage rhombohedron showing a twinning lamella (c) parallel to the base $c(0001)$, and three incipient cleavages $\left(c l_{1}, c l_{2}\right.$, and $\left.c l_{3}\right)$, which have the same positions as the twinning lamellae parallel to

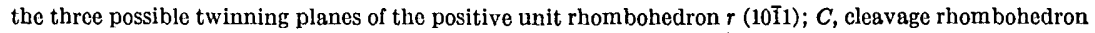
showing twinning lamellae parallel to the three twinning planes of the negative rhombohedron $f(02 \overline{2} 1)$, shadow layers $(s l)$ formed along crystal faces during growth, and cavities $(l g)$ filled with liquid and gas. Twinning lamellae of the type shown in $A$ are abundant in the Mexican calcite examined. 
twinning lamella. The effect is one that would be produced by cutting from a crystal a thin slice parallel to a twinning plane, rotating the slice $180^{\circ}$, replacing it, and gluing the crystal back together again. The thickness of twinning lamellae is generally less than a millimeter and may be only a few hundredths or a few thousandths of a millimeter. It is not necessarily uniform but may vary in a steplike or wedge fashion (fig. $13 A$ ), the wedge being formed actually of submicroscopic steps. Twinning lamellae may terminate within a crystal against a fracture or a twinning lamella in another direction, or by wedging out. They may grow with the crystal, or be formed afterwards in adjustment to internal strain caused by external stresses.

The types of twinning plane on which twinning lamellae may form are the same as those on which twin crystals form. (See p. 123.) A twinning lamella parallel to the base $c(0001)$, the first type of twinining plane, is shown in crystal $B$ in figure 13. Although such lamellae are said to occur commonly in crystals in deposits in the State of Montana in the United States, none were seen in the Mexican deposits examined. The three possible positions of twinning lamellae parallel to the faces of the form $r$ (1011), the second type of twinning plane (p. 123), are illustrated by the three incipient cleavage fractures in crystal $B$ in figure 13. The third type of twinning plane, parallel to the faces of the form $f(02 \overline{2} 1)$, permits twinning in three directions, as in crystal $C$ in figure 13. No twinning lamellae of types two and three were seen in the Mexican calcite. The fourth type, parallel to the faces of the obtuse negative rhombohedron $e(01 \overline{1} 2)$, also permits twinning in three directions, as in crystal $A$ in figure 13. Most of the crystals in the Mexican deposits have this type of twinning lamellae in one or two directions, but none were seen with these lamellae in three directions. These $e(01 \overline{1} 2)$ lamellae are produced easily in small cleavage rhombohedrons by a firm pressure on any two opposed edges, and even lamellae in all three directions can be thus produced.

\section{PHYSICAL, OPTICAL, AND CHEMICAI PROPERTIES}

Calcite has highly perfect cleavage in three directions. In other words, when struck properly it will part, or cleave in three directions and yield flat mirrorlike parting surfaces. These directions are parallel to the faces of the positive unit rhombohedron $r$ (10ī1). (See fig. $8 A$.). Consequently, any fragment of calcite bounded by six cleavage faces is similar in appearance to the natural rhombohedron, even though all the faces may not be of the same size, and it is called a cleavage rhombohedron. (See fig. 13 and fig. $14 \mathrm{~A}$.) This characteristic makes it possible and relatively easy to cleave and select optical calcite in the field. Crystals with twinning lammellae cleave 
with much greater difficulty than crystals without them. Besides cleaving, some calcite will part along twinning lamellae whose twinning plane is $e(01 \overline{1} 2)$ (fig. $13 \mathrm{~A}$ ), but such parting is difficult to obtain. Fractures not parallel to a cleavage direction or a plane of parting are conchoidal; that is, they are similar to the fractures characteristic of quartz and obsidian. Conchoidal fractures are difficult to obtain, but several crystals similar to $E$ in figure 14 were seen with such fractures perfectly developed.

Calcite is number 3 in Moh's scale of hardness; it cannot be scratched by the finger nail but is easily cut or scratched by a knife blade. Its specific gravity is 2.71 , slightly greater than that of quartz. Its luster generally is subvitreous-nearly like that of glass-or slightly less vitreous than that of quartz. In the commercial deposits in Mexico, clear transparent crystals are colorless, pale yellow to brown, or less commonly pale violet, the color occurring in well-defined layers. Cloudy layers in otherwise colorless crystals are generally white, more rarely they are reddish brown, black, or green. In these deposits the clear colorless crystals do not fluoresce under ultraviolet light, but the yellow crystals fluoresce pale to bright yellowish green and the cloudy crystals pale to bright yellowish green or red. The crystals that fluoresce are also phosphorescent.

Calcite, as a mineral of the hexagonal crystal system, has the capacity to resolve all light that enters or passes through it into two rays polarized in planes at right angles to each other; one of these planes is always parallel to the direction of the vertical crystal axis. But if the light is transmitted in the direction of the vertical crystal axis, it is not resolved into separate rays and is not polarized. The two polarized rays travel through the crystal with distinctly different velocities, and accordingly they are refracted differently. This difference is greatest when light travels normal to the vertical crystal axis, and it becomes less as the direction of transmission approaches the direction of this axis, disappearing when the two coincide.

The great maximum difference in the velocities of the two polarized rays gives rise to an optical phenomenon characteristic of cleavage rhombohedrons: if such a rhombohedron is placed over a dot on a piece of paper, two dots will appear, one of them apparently off to one side and slightly higher than the other. The distance between the dots depends on the thickness of the rhombohedron. However, if a clear crystal with prism faces is placed over the dot in such a way that one prism face is flat against the paper and the observer is looking through the opposite face, the two dots will appear to be one, though there are actually two, one above the other. But if a clear basal plate is laid over the dot, actually only one dot will be present. Because of the great maximum difference in the velocities of the two 
rays, it is possible by properly cutting a crystal to make a compound prism that will reflect and absorb one of the two rays and transmit light polarized only in one plane, which is the basis of the principal use for calcite.

If a slice of calcite cut parallel to the base $c(0001)$ is placed between two plates, arranged at right angles to each other, of a substance that transmits polarized light in only one direction, a characteristic figure appears. This figure, known as a uniaxial interference figure, consists of a series of concentric color rings over which a black Maltese cross appears to be superposed. This effect may be produced by using two plates of the manufactured glass, Polaroid. The capacity of calcite to produce a certain type of interference figure under special conditions was utilized by the Polaroid Corporation in developing a new important use for optical calcite in 1942.

Calcite is composed principally or entirely of calcium carbonate $\left(\mathrm{CaCO}_{3}\right)$. In some varieties the calcium is replaced to a small extent by magnesium, iron, manganese, or one of several other metals, but in the clear colorless crystals used for optical purposes such replacement is not common. Clear yellow crystals may contain a small percentage of iron, but the color usually disappears on long exposure to sunlight. The cloudy layers in otherwise clear crystals contain minute grains of other substances: the black clouds probably contain grains of manganese oxide, the reddish-brown clouds grains of iron oxide, and the white clouds grains of silica. The cloudy white layers also contain minute cavities. Presumably these white clouds are due principally to microscopic grains of silica, for an assay of the cloudy part of an otherwise clear crystal gave 0.02 percent of silica $\left(\mathrm{SiO}_{2}\right)$. Cavities are abundant in crystals in some of the commercial deposits. They range in size from tiny ones so small that they cannot be distinguished by the naked eye to large ones more than fivecentimetersin length. They are more or less angular, as shown in crystal $C$ in figure 13 , and generally they contain a liquid with a small bubble of gas. The liquid in the crystals from southwestern Chihuahua is much like ordinary water to the taste. It is probably similar to the liquid from which the crystals precipitated. The gas may be carbon dioxide $\left(\mathrm{CO}_{2}\right)$, which was probably dissolved in the liquid.

\section{OPTICAL CALCITE \\ TERMS APPLIED, USES, AND SPECIFICATIONS}

Optical calcite, which, as the name implies, is calcite used for optical purposes, generally has been called Iceland spar because it was first mined in Iceland. Iceland spar is crystalline calcite of the highest degree of natural purity and clarity. Since most of the calcite discussed in this report is somewhat lower in quality, though used for 
optical purposes, it is more convenient to refer to all of it as optical calcite. Where a distinction is made, the material generally called Iceland spar will be called high-grade optical calcite, and crystal of lower quality will be called suboptical calcite.

High-grade optical calcite is used principally in polarizing prisms for petrographic microscopes, dichroscopes, polariscopes, saccharimeters, colorimeters, and photometers. Such prisms are generally called Nicol prisms, for they were first designed by William Nicol, although several modified types have been designed since. The calcite used in polarizing prisms must be colorless, perfectly clearthat is, without clouds, cavities, or microscopic inclusions-free from twinning lamellae, and free from cleavage fractures, and the pieces must be above a specified minimum size. Buyers seldom take cleavage rhombohedrons of high-grade optical calcite that are smaller than 1.8 by 1.8 by 3.5 centimeters, measured along the edges, and that weigh less than one ounce; the rhombohedron should measure at least 3.5 centimeters along one edge. The size of a cleavage rhombohedron is most easily determined by choosing any corner and measuring the lengths of the three edges leading from it.

Suboptical calcite has been used principally in the manufacture of Optical Ring gun sights, for which purchases were sharply curtailed after November 15, 1944. Small quantities are used for other purposes that do not require calcite with as high a degree of clarity as that required by polarizing prisms. Schools and colleges use it for demonstrating certain optical principles, and museums and mineral collectors purchase small quantities for their collections. However, well-formed crystals, regardless of the quality of the calcite, are in greater demand for mineral collections than are clear cleavage rhombohedrons. A small quantity of suboptical calcite is used by some chemical laboratories to prepare standard solutions for volumetric analysis, although for this purpose any pure calcium carbonate would do. For all other significant uses of calcite, other more commonly and abundantly occurring lime rocks can be used, obtainable at much less cost. The waste of crystal calcite can be used, of course, for any purpose served by lime rock.

Material used in the manufacture of Optical Ring gun sights, like high-grade optical calcite, must be free from twinning lamellae and cleavage fractures, but it could be slightly colored and could have very faint clouds if the cloudy layers were near the corners of the piece. Easily visible inclusions and cavities not in the corners destroy the usefulness of the piece. Cleavage rhombohedrons were accepted with small fractures and twinning lamellae in the obtuse corners-the corners from which a line parallel to the vertical crystal axis emerges. (See fig. 14 $A$.) The cleavage rhombohedron of minimum size accepted 
was 2.86 centimeters along each of its three dimensions. The minimum diameter of a crystal with natural faces elongate in the direction of the vertical axis had to be a little greater.

Drawings $A, B$, and $D$ in figure 14 illustrate the smallest cleavage rhombohedron of suboptical calcite accepted by the Polaroid Corp., and the approximate positions and thicknesses. of the cuts made. These drawings are of actual size though some of the edges are foreshortened in projections $A$ and $B$. From these drawings the reader can judge just where flaws or defects could occur that would not destroy the value of the piece. As the slices were cut normal to the vertical (c) crystal axis, he can judge also the size of the smallest piece of irregular shape that could be used. Because of the direction in which the final slice was cut, natural basal plates, such as the one shown in figure 15, could be used if the clear part was slightly thicker than half a centimeter. Such crystals gave much less waste than cleavage rhombohedrons.

\section{COMMON DEFECTS AND THEIR RECOGNITION}

The most common defects in otherwise apparently clear marketable calcite are twinning lamellae and twinning planes, cleavage fractures, inclusions and cavities, and very faint cloudy layers not readily visible in daylight. Twinning lamellae are not readily apparent to the untrained observer, but they can always be recognized by using a few simple criteria. Because twinning lamellae are. very thin and are oriented optically in a position different from the rest of the crystal, light as it passes through is interfered with and partly destroyed, giving rise to rainbow colors, called interference colors, which are seen best in certain positions found by rotating the piece. A lamella that has the same thickness throughout will show only a single color, but a lamella that varies in thickness will show a succession of color bands. If the lamella is wedgelike, which is generally the case, the color bands will follow one another in a definite order, which is beginning at the thin edge of the wedge: gray-yellow-red, blue-greenyellow-red, blue-green-yellow-red, blue-etc. With each succeeding set of bands the colors will become paler and finally disappear, the lamella then appearing white or mirrorlike.

The twinning lamellae, and consequently the planes of color, have positions within the crystal different from those of the faces of the cleavage rhombohedron, unless they are of the $r(10 \overline{1} 1)$ type, in which ruro caso tho lamollae are parallel to the cleavage faces. With this exception the lamellae may be described as cuuting neariy dingonall through the cleavage rhombohedron. (See fig. 13.) The intersection of an $e(01 \overline{1} 2)$ lamella, by far the most common type in Mexico, with 

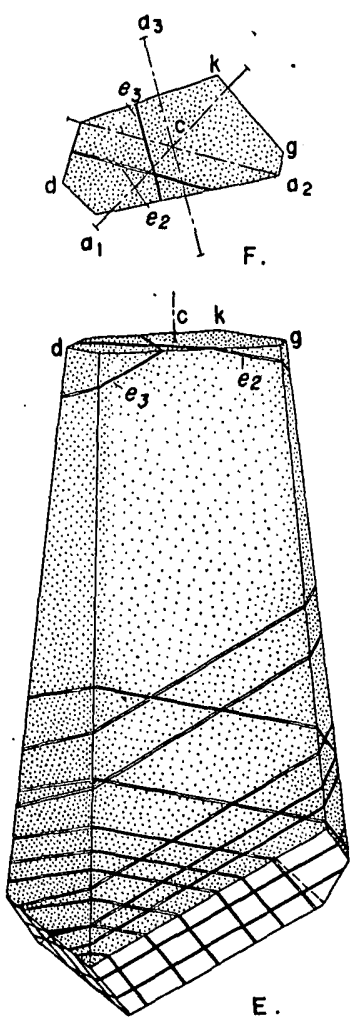

E.
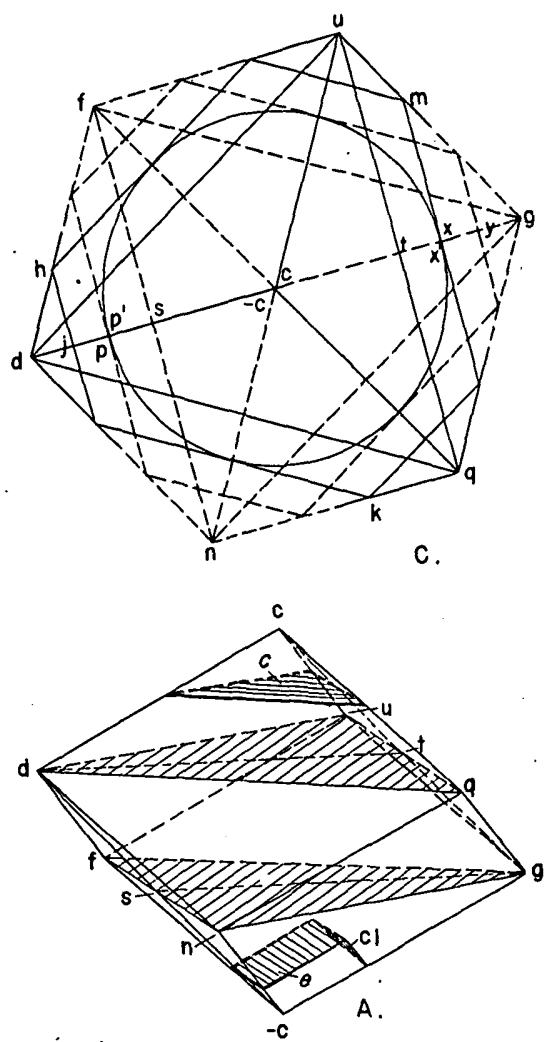
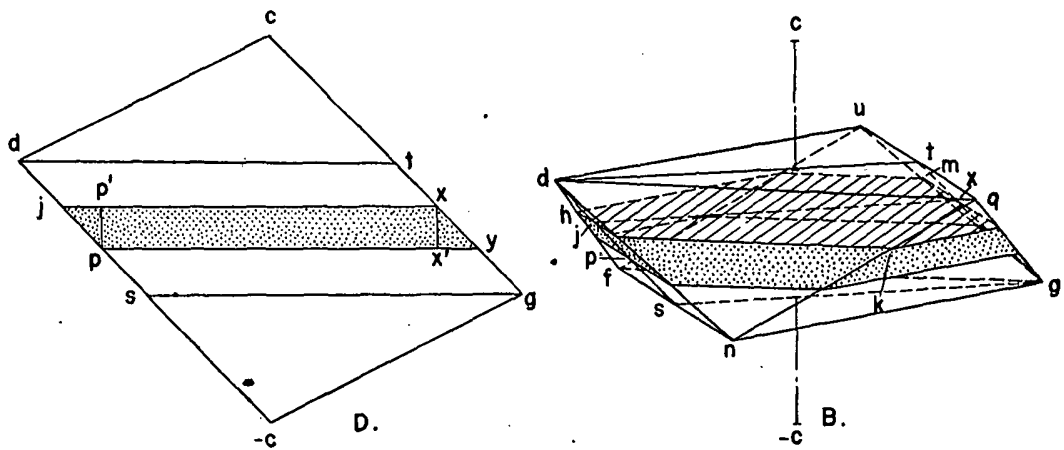

Figure 14.-Drawings of cuts made from smallest cleavage rhombohedron accepted for suboptical use, and of a common crystal habit in southwestern Chihuahua. $A$, smallest cleavage rhombohedron accepted for suboptical use (actual size, though some edges are foreshortened because of type of projection), illustrating twinning lamellae of the $c(0001)$ type $(c)$ and the $e(01 \overline{1} 2)$ type $(e)$, a cleavage fracture $(c l)$, and first rough cut (between planes $d q u$ and $f n g) ; B$, rough cut of $A$, illustrating position of a possible finished cut (layer represented by stippling on front faces); $C$, top view of $A$ and $B$ combined, showing circular outline of finished cut of maximum diameter: lines above center are solid, those below broken; $D$, vertical section of $C$ in the plane djps-cgyxtc, showing true thicknesses of cuts and true angles; $E$, crystal habit (distorted scalenohedron with base) typical of calcite in southwestern Chihuahua, showing twinning lamellae $\left(e_{2}\right.$ and $\left.e_{3}\right)$ parallel to two of the three possible twinning planes of the form $e(01 \overline{1} 2) ; F$, top view of $E$. 

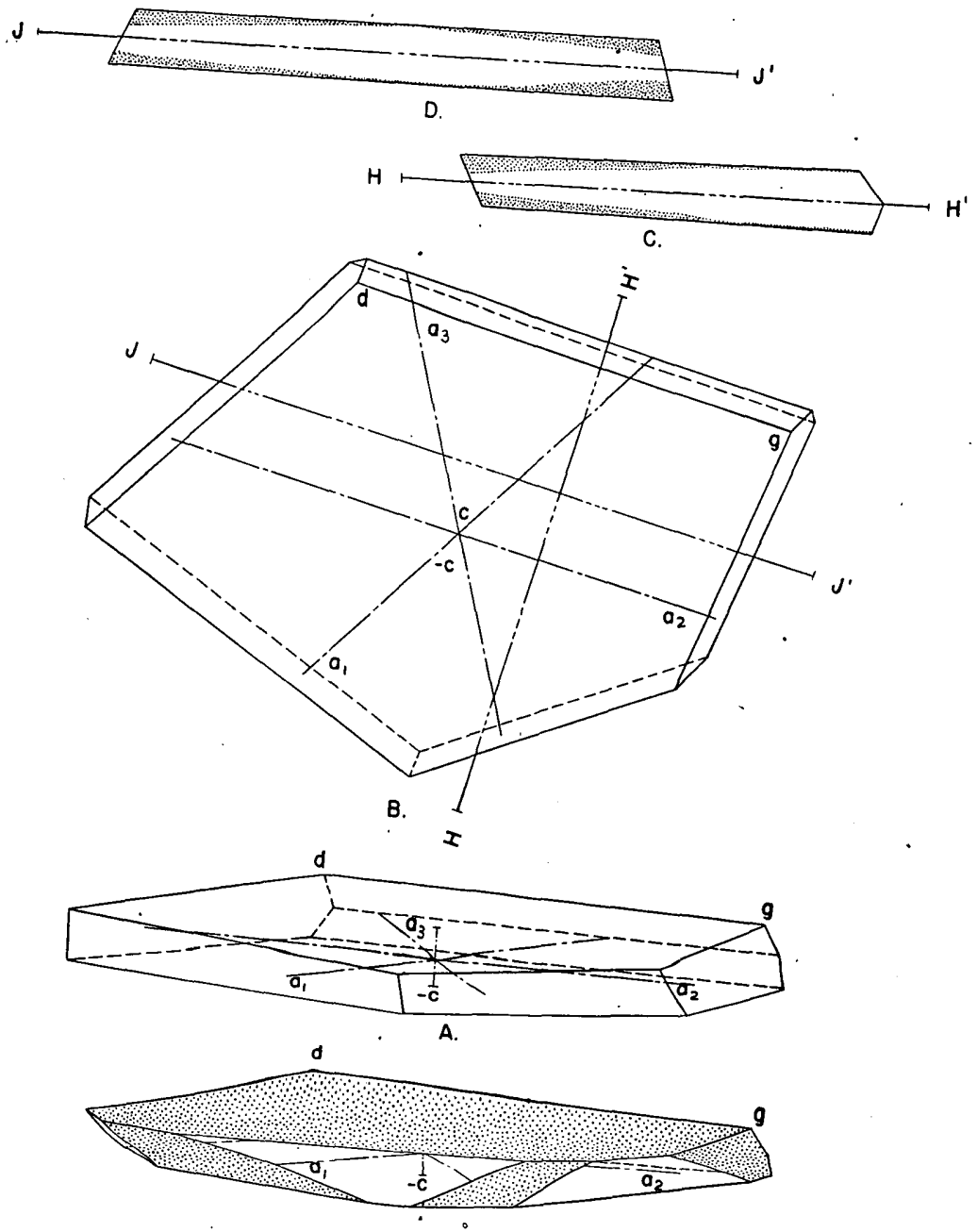

E.

FrauRE 15-Drawings of a plate of calcite typical of those in the $\mathrm{La}$ Fe deposit near Rodeo, Durango. $A$, clinographic projection of crystal plate: note that top and bottom faces are not parallel and merely sim. ulate the base $c(0001)$, and that all other faces are not natural crystal faces but merely terminations formed by growth interference against other plates in the boxwork structure in which the crystals formed; $B$, top view of $A ; C$, vertical section through $B$ along line $\mathrm{HH}^{\prime}$, showing irregular layers of cloudy calcite (stippled) in upper and lower parts of crystal; $\boldsymbol{D}$, vertical section through $B$ along lino $\mathrm{JJ}^{\prime}$, showing cloudy layers (stippled); $E$, same as $A$, illustrating positions of the three cleavages (faces not stippled).

a cleavage face is expressed on that face by two faint nearly parallel lines, called striations. These lines are the intersections of the cleavage face of the rhombohedron with the cleavage face of the differently oriented lamella. The distance between the two parallel lines (the striations) depends upon the thickness of the lamella, which is commonly so thin that the two lines appear as one. The striations caused 
by the ordinary $e(01 \overline{1} 2)$ type of twinning lamella are parallel to the edges of two of the faces of the cleavage rhombohedron and cut diagonally across the other two, as illustrated in drawing $A$ in figure 13. Cleavage fragments of twin crystals that include the twinning plane have cleavage faces in more than three directions, as shown in the drawings in figure 11. With these few criteria in mind, the observer should have no difficulty in recognizing twinning in cleavage rhombohedrons.

Fractures parallel to the three directions of cleavage are generally present in some parts of all calcite crystals. Such fractures may result from internal strain that cannot be relieved by twinning, such as strain caused by geologic deformation in the past, or they may result from shock during mining and subsequent handling of the crystals. As a cleavage fracture admits a very thin film of air, light is totally reflected when the fracture is viewed from a certain position and the fracture then appears like a mirror. If the observer will hold a cleavage rhombohedron in front of him in such a position that one face is toward him and another is approximately toward the sky and will then rotate the piece back and forth slowly, any cleavage fracture parallel to the top face will appear as a mirror within the crystal. Fractures parallel to either of the other two directions of cleavage can be found similarly by alternately turning the other two different faces toward the sky. The effect is best obtained by looking toward a dark background. During this procedure twinning lamellae also will be found and seen most readily. Because of double refraction in calcite, any fracture well within the crystal will appear as two fractures.

A cleavage fracture that is only partly open will not appear as one complete mirror surface but rather as a group of connected irregular mirror spots. This is the most common type of fracture, and it is called an incipient cleavage fracture. A fracture that is well open will show bands of interference colors similar to those along a twinning lamella, when the observer looks in a direction nearly normal to the fracture surface. The plane of the color bands is always parallel to a face of the cleavage rhombohedron, thus differing from the position of the plane along the ordinary type of twinning lamella, and unlike the color bands along twinning lamellae, these bands can be made to move by pinching the fracture closed.

Large inclusions and cavities are easily recognized as such, and because of the doubly refracting character of calcite, each inclusion or cavity will appear as two, the distance between the two depending upon the depth within the crystal. Clouds, which are very difficult to detect when faint, consist of inclusions and cavities arranged in layers in positions corresponding to faces of the crystal during growth. 
If a cleavage rhombohedron with faint cloudy layers is inspected in a direction more than slightly inclined to the direction of the layers, either no clouds will be seen or the entire piece may appear to be faintly cloudy. Even though a piece may appear slightly cloudy when viewed in some directions, a part of it might be used if trimmed properly; hence it is necessary to locate the exact positions of the layers. This is best done by looking through the piece toward a dark background and turning it slowly in all directions. When the direction of view nearly coincides with the plane of a cloudy layer, the layer is clearly visible and seems to be formed of two diverging planes-because of double refraction-that join in the face nearest the observer. Suboptical calcite with cloudy layers faintly visible in daylight was accepted if the layers were near the edges of the cleavage rhombohedron.

High-grade optical calcite must not contain any cloudy layers. As the presence of very faint layers cannot always be detected in daylight, a special method of examining the crystal is used: by flashing a bright narrow beam of light through a cleavage rhombohedron in the dark, an observer looking at right angles to the beam will note a faint white fog in its path where clouds are present. The effect is much like that of dust, fog, or smoke in the beam of the headlight of an automobile at night. In the field, a beam may be produced by a small battery pen light or by concentrating the light of any source with a small biconvex magnifying lens, such as a reading glass. If no clouds can be detected by this method, the calcite is probably of high-grade optical quality, though it must, of course, fulfill the other requirements given on page 131 .

\section{CONSUMPTION, MARKETS, AND PRICES}

Consumption of optical calcite in the United States in the decade before 1940 probably never exceeded 200 pounds a year, but consumption in the rest of the world probably was much greater. Germany undoubtedly was the principal consumer; England, France, Switzerland, and some other European countries used smaller amounts. After the development of the Optical Ring gun sight the consumption of suboptical calcite rose sharply, and in 1943 and 1944 it was at the rate of about 10,000 pounds a year. At the same time the consumption of high-grade optical calcite also increased in the United States. At the end of the war consumption of optical calcite decreasod sharply. although it may continue to be greater than before the war. Synthetically manufactured crystals of sodium 'nitrate $\left(\mathrm{NaNO}_{3}\right)$ have been found usable in gun sights and may replace calcite for that purpose. The synthetic material Polaroid has been found to give satisfactory 
results in Nicol prisms and may replace a part of the calcite formerly used for prisms.

Markets for optical calcite have always been uncertain. The principal steady buyers of high-grade optical material in the United States are the Bausch \& Lomb Optical Co., of Rochester, N. Y., and the Spencer Lens Co., of Buffalo, N. Y.; the principal buyer of suboptical material during 1943 and 1944 was the Polaroid Corp., of Cambridge, Mass. ${ }^{4}$ Other buyers of calcite make purchases as the need arises. Such buyers include museums, schools, mineral collectors, mineral dealers, chemical laboratories, and companies manufacturing optical goods.

The price of high-grade optical calcite varies widely, depending partly upon the urgency of the need and partly upon the size and quality of the individual pieces. The quality can be closely judged only by a trained observer in the laboratory. High-grade optical calcite in pieces weighing less than a pound have sold during the past few years for from $\$ 5$ to $\$ 40$ a pound, but very large pieces have sold for much more. The following list of prices quoted late in 1944 by the Bausch \& Lomb Optical Co. are typical and illustrate the great effect of size and quality on price.

Prices of high-grade optical calcite quoted in 1944

\begin{tabular}{|c|c|c|}
\hline \multirow{2}{*}{ Size of piece } & \multicolumn{2}{|c|}{$\begin{array}{l}\text { Price per pound (U. S. } \\
\text { currency) }\end{array}$} \\
\hline & First grade & Second grade \\
\hline $\begin{array}{l}\text { From } 1 \text { ounce to } 2 \text { ounces } \\
\text { From } 2 \text { ounces to } 4 \text { ouncess } \\
\text { From } 4 \text { ounces to } 8 \text { ounces. } \\
\text { More than } 8 \text { ounces }\end{array}$ & $\begin{array}{r}\$ 15 \\
20 \\
30 \\
40\end{array}$ & $\begin{array}{l}\$ 5 \\
10 \\
15 \\
20\end{array}$ \\
\hline
\end{tabular}

There had been no well-established market for suboptical calcite until late in 1942. At that time the Polaroid Corp. began to make large purchases, and by 1944 it had established the price of material, judged by examination in its laboratories to be usable, at $\$ 7.50$ a pound. Purchases of suboptical calcite by independent buyers, from 1940 until 1945, had been made at prices ranging from $\$ 0.50$ to $\$ 12$ per usable pound. Since November 1944, when the Polaroid Corp. discontinued its purchases of suboptical material, there has been no established price.

\section{GEOLOGIC CHARACTER OF DEPOSITS}

There is good evidence to conclude that optical calcite can occur in rocks of virtually any composition, either igneous, metamorphic, or sedimentary; either consolidated or unconsolidated; and of any

\footnotetext{
4 For a more complete list of the names of buyers, see Hughes, H. H., Iceland Spar and optical fluorite: U. s. Bur. Mines Inf. Circ. 6468R, pp. 7-8, February 1941.
} 
age from pre-Cambrian to Recent. However, known occurrences strongly indicate that extrusive volcanic rocks, particularly those of moderately basic composition such as andesite and basalt, and wellconsolidated rocks are more favorable to the occurrence of commercial deposits than are others. Better than rock type as a guide to the location of commercial deposits is proximity to areas of volcanic activity in geologically recent time. As volcanic rocks cover much of the surface of such areas, commercial deposits generally, though not necessarily, occur in volcanic rocks. Furthermore, wherever the age of a commercial deposit could be determined closely, it has proved to be geologically recent, ranging from late Teritary to Quaternary. Although some optical calcite probably was deposited during much earlier geologic time, there is doubt whether those deposits could have escaped destruction by the many forces acting upon them during the subsequent ages. The occurrence of a commercial deposit in pre-Cambrian rocks is not precluded, however, for the calcite itself could have been deposited during Quaternary time in rocks of preCambrian or later age. It is significant that no calcite of optical quality has ever been found, so far as the writer knows, among crystals in caverns formed by ground-water action in limestone, or among crystals known to have been deposited from cold ground waters, although there seems to be no reason why usable crystals should not be formed by such processes now and then.

In Mexico, high-grade optical calcite has been found in basalt flows in northeastern Chihuahua, in rhyolite and latite flows and breccia in southwestern Chihauhua, in andesitic rocks in western Durango, and in a brecciated fault zone between limestone and shale in eastern Sonora. Suboptical calcite has been found chiefly in rhyolite and latite flows and breccia in southwestern Chihauhua and in central Durango, although the deposits in basalt flows in northeastern Chihuahua, and a deposit in andesitic conglomerate in eastern Sonora, have yielded a moderate amount. The age of these rocks ranges from early Tertiary to late Quaternary, the andesitic conglomerate - valley fill-being the youngest.

In the United States, the most productive deposits are found in basalt flows in southern California, in moderately basic volcanic rocks in western Montana, and in hornblende schist ${ }^{5}$ in northern New Mexico. In other parts of the world, the most productive deposits known and described occur in basalt in Iceland, and in weathered diabase ${ }^{6}$ in South Africa.

The structural environment is probably next in importance to the proximity to areas of geologically recent volcanic activity in deter-

S Kelley, Vincent C., Iceland spar in New Mexico: Am. Mineralogist, vol. 25, p. 358, 1940.

${ }^{6}$ Hughes, H. H., Iceland spar and optical fluorite: U. S. Bur. Mines Inf. Circ. 6468R, p. 10, February 1941. 
mining where a commercial deposit is likely to occur. Calcite of optical quality rarely, if ever, is found in a vein or deposit completely filled with minerals: generally it occurs in openings, such as an open fracture or fault fissure, an elongate or pipelike mass of breccia with large openings, a cave or other irregular cavity formed in a lava flow by flowage when the lava was extruded, or a cavity formed at least in part by solution of the enclosing rock. Most of the Mexican deposits are in open fractures and fault fissures, as are the largest ones in the United States. The deposit near Cumpas (9, plate 23) in eastern Sonora, is in an irregular zone of breccia believed to have been formed partly by faulting and partly by collapse of solution caverns. ${ }^{7}$ The deposit in northern New Mexico, in the United States, is in a piplike mass of breccia, according to Kelley. ${ }^{8}$ The deposits of Iceland are in irregular cavities in basalt flows, formed probably during their extrusion, and in open fissures. The South African deposits are interpreted as occupying open fissures.

The fissures containing optical calcite in eastern Sonora and in southwestern Chihuahua trend nearly northwest. Generally they are faults, though not necessarily major ones, parallel to the common block-fault structure of the region. The veins in central Durango trend nearly north, the major structural trend there. Some good calcite has been found in short cross fissures and branches of the main veins. The faults in all these areas reflect the most recent structural movements and were formed probably late in Tertiary and during Quaternary time.

\section{COMMERCIAL DEPOSITS}

Commercial deposits of optical calcite contain virtually no minerals but calcite. It is significant that no optical calcite is found in metalliferous deposits containing calcite crystals, although it is possible that pieces might be found occasionally. Near the surface, most commercial deposits contain soil, clay, caliche, or other debris washed into the openings in the veins by descending rain water (pl. $24 F$ ), and where the openings are connected, the debris may extend to a depth of several meters. This material is not an essential part of the deposits, and the assumption should not be made, as is commonly done, that the debris was deposited concurrently with the calcite or that the calcite crystallized or formed in it.

Individual crystals range in weight from a small fraction of an ounce to as much as a ton, but crystals heavier than 80 or 85 pounds are not common.

7 Wiese, John H., manuscript report in fles of the U. S. Geological Survey.

- Kelley, V. C., Iceland spar in New Mexico: Am. Mineralogist, vol. 25, p. 359, 1940. 


\section{SHAPE AND SIZE}

In all places where sufficient work has been done to expose some of the limits of a commercial deposit, it is found that the shape is more or less the same, although the size differs from one deposit to another. The openings in which optical calcite is found are in lenticular bulges in veins, or in lenticular or pipelike masses of calcite, and consequently the deposits are lenticular. Individual openings, called "abras" in Chihuahua, range in length from somewhat less than a meter to more than 30 meters and from a few centimeters to more than 2 metèrs in width. Characteristically, a vein that pinches shut, thus terminating a cavity, opens up again farther along the strike or dip. Naturally the size of a commercial deposit-the extent to which a deposit can be mined profitably-depends upon the distance between the openings; where they are close together, as along a part of the El Porvenir vein near Areponápuchic, Chihuahua (pl. 25), dead work can be carried on without loss, but where they are far apart such work does not pay. The distance between openings cannot be predicted, although experience in a particular district may aid in determining how great it may be. Generally it has not paid to do more than a few meters of dead work to discover another opening after one has been worked out.

Owing to the very small scale on which calcite is mined, the ultimate extent of most commercial deposits has not been determined and cannot be foretold accurately. The most extensive mining and exploration in Mexico has been done near Areponápuchic (2), Chihuahua (pl. 27), along the El Porvenir (pl. 25) and the La Aurora (pl. 26) veins. The vertical extent of connected workings along the El Porvenir vein is about 50 meters, and if other small unconnected workings are considered, the vertical extent is 105 meters. The vertical range of mining along the La Aurora vein is 100 meters. Most of the other deposits have been mined to depths of less than 10 meters and many to depths of less than 3 meters. The longest veins are continuous for 1 or 2 kilometers, as, for instance, some of those in southwestern Chihuahua (pl. 27) and in northeastern Chihuahua (pl. 28), and some may extend even farther, but the greater number are much shorter, generally less than 100 meters. Pockets of commercial calcite do not occur along the entire length of a given vein but only in certain sections along it.

STEVCTURES FAVORABIE TO OCCURRENCE OF OPTICAL CALCITE

Since optical calcite occurs in openings in rocks, anly structuro that provides such openings is favorable to its deposition. Although most fault fractures are tightly closed, an opening is likely to form where the fault plane bends along the strike or dip. Such a bend occurs along the strike of the El Porvenir vein (pl. 25) and along the dip of the La 
Esmeralda vein (pl. 29), as illustrated diagrammatically in $A$ and $D$ in plate 24. The wall rock of the outside curve of the bend, or of the hanging. wall, is usually fractured and contains ramifying open fissures partly filled with calcite.

Other favorable structures are: (1) a cross fracture between two faults, as in the La Fe deposit (pl. 30); (2) the intersection of two fissures, as in the Bacadéhuachic deposit (pl. $24 C$ ); (3) a swelling along a straight vein; (4) the junction of a branch vein with the main vein; (5) the junction of the two branches of a divided vein; and (6) a section not filled with calcite in an otherwise straight narrow fissure, as shown in $E$ in plate 24 . Less common favorable structures, not actually fissures (not illustrated), are: (7) a lenticular mass of open breccia, as in the Cumpas deposit in eastern Sonora; (8) an open breccia pipe, as in northern New Mexico in the United States; (9) a naturál cave or cavity in a lava flow, as in the deposits of Iceland; and (10) a cavity formed by solution of a soluble rock. Although two of the favorable structures-8 and 9 -were not seen in the deposits examined in Mexico, they are mentioned here as a guide to prospecting. The detailed structure typical of a small deposit is shown in drawing $F$ in plate 24 .

\section{FACTORS AFFECTING QUALITY OF CALCITE}

The calcite in any one vein or district is more or less uniform in habit, quality, and types of defects. Although crystals in varions unconnected openings along the same vein vary slightly in quality and proportion of defects, sufficiently sometimes to make the difference between a profitable or an unprofitable mining operation, in general a high degree of uniformity is to be expected. This uniformity undoubtedly reflects the uniform nature of the liquid from which the calcite was deposited and the uniform physical conditions under which it formed.

The chemistry of the mother liquid is probably the most important single factor influencing the quality. If calcite of optical quality is to be deposited, the liquid apparently has to be relatively simple chemically and contain little else than the elements necessary to form calcium carbonate. Accordingly, veins in which other minerals occur are not likely to contain optical calcite in commercial quantities, nor are deposits formed from descending surface water, such as those in limestone caverns. That a slight variation in the composition of the liquid occurred from time to time during the period of deposition is indicated by the repeated alternation of layers of cloudy and clear calcite, but some slight variation might be expected. If the crystals from a newly opened deposit are found to contain black or reddishbrown clouds, which make them unusable, the crystals in the rest of 789679-48-3 
the deposit may be assumed to be equally unsuitable for optical use. If all the crystals in a part of the deposit contain dense white clouds, there is no reason to expect that continued exploration will be profitable, although some parts of the deposit may contain clear crystals if the white clouds are faint.

The composition of the rock in which the deposit occurs probably has some effect on the quality of the calcite deposited, but how great an effect is not clear. In all the deposits studied by the writer, basic rocks-those high in lime and low in silica-either enclose the deposits or lie at shallow depths below them. The effect of limestone and marble as enclosing rocks on the quality of the calcite deposited is not at all certain. Although there seems to be no good reason why the presence of limestone should affect, the quality adversely, commercial deposits in limestone are rare; the only one known to the writer that has yielded optical calcite is that near Cumpas (9), Sonora. Most of the calcite found in openings in limestone was deposited either by descending surface waters or in metalliferous veins at moderate to great depth, deposits that would not be expected to contain optical calcite anyway. Possibly the lack of deposits in limestone may be related to the fact that commercial deposits are located in areas of geologically recent volcanic activity where the sedimentary rocks generally are thickly covered by volcanic rocks. In such areas the calcite would be deposited only in the volcanic rocks near the surface.

The depth at which the calcite is deposited undoubtedly has an effect on its quality. In southwestern Chihuahua, where a vertical section of 1,600 meters is exposed in the canyons of Río Urique and Río de Oteros, the commercial deposits occur in the upper half of the canyon walls though well below the top. Above the commercial deposits the calcite seems to disappear. Deeper in the canyons the veins are narrower or completely filled with calcite, and the crystals are filled either with dense white clouds or with abundant twinning lamellae and incipient cleavage fractures. It is natural to expect a fissure to be less open with increase in depth and to be filled with calcite first at depth. Furthermore, crystals deposited at a depth of 1,000 meters from the surface would be subject to a static pressure of roughly 100 kilograms per square centimeter, because of the column of water above. Whether the subsequent removal of this pressure produces twinning lamellae and incipient cleavage fractures is not known but seems a reasonable inference. At any rate, some crystals are quite definitely under strain, possibly as a result of this change in pressure or because of slight differences in chemical composition between the inner and outer parts of the crystal, for small incipient cleavage fractures in pieces from which the waste has been trimmed have been noted to enlarge gradually of their own accord. Once the 
strain is relieved, however, no further enlargement occurs. This feature is common in crystals from only a few of the deposits.

Earthquakes and earth movements undoubtedly have destroyed much optical calcite. They would not greatly affect crystals in cavities, although they might break some of the heavy large crystals from the walls, but their effect would be particularly disastrous in completely filled veins. There the stresses set up would produce abundant twinning lamellae and cleavage fractures. For this reason nearly all optical calcite in deposits that were formed in geologically ancient times was probably destroyed. Descending surface waters gradually dissolve crystals over which they pass, as proved by the complete: removal of crystals from water courses in some deposits. Such solution, however, apparently has no effect on the quality of the calcite left, since usable pieces can be obtained from corroded crystals.

The quality of the calcite is remarkably unaffected by weathering. Contrary to general belief, usable optical calcite is commonly found as surface float. In fact, unless some pieces of the float are of optical quality, no matter how small the pieces, further exploration is not warranted. However, there may be no float in humid climates or where the soil mantle is thick, for rain water gradually dissolves it. Also contrary to general belief, natural temperature changes and sunlight apparently have.little or no effect on quality, for large usable pieces have been found on the surface in semiarid regions where they had been exposed for years to low temperatur es at night and the burning heat of the bright sun during the day. A crystal that is under internal strain, as some apparently are, probably would fracture under these conditions, but it would also fracture when trimmed. If a cold crystal were suddenly placed in hot water or in the hot sun, fractures might develop, although the writer has not seen fractures develop in crystals that were subjected to a moderately great temperature change, such as placing a cold trimmed piece in the hot sunlight.

\section{ORIGIN}

Optical calcite is believed to be deposited generally in channel ways or fissures leading to hot springs on the surface. Evidence pointing to its deposition by ascending hot water rather than by descending cold surface water seems conclusive.

1. Optical calcite does not occur in deposits that unquestionably have been deposited by cold ground water; such calcite generally consists of masses of small crystals, mainly stalactites and stalagmites.

2. Surface waters more commonly dissolve calcite than deposit it.

3. Uniform crystal habit, quality, and types of defects in the calcite found in each district point to the uniform nature of the source liquid. 
4. The purity of the calcite and the relative freedom from inclusions and dirt attest the simple chemical composition of the mother liquid, a simplicity not likely to be found in surface waters.

5. The rock in the walls of the deposits commonly is strongly altered to distances of a few centimeters to more than a meter. The altered rock is bleached light gray, is soft, and contains a high proportion of clay, features which indicate a prolonged hydrothermal activity. On the other hand, the clay and debris found in many deposits are not a result of this activity, however, but were carried in later by ground water.

6. The presence of zeolites on some of the calcite in Iceland ${ }^{9}$ and

7. the inclusions of chalcopyrite in some of the calcite of New Mexico ${ }^{10}$ definitely indicate hot water as the source of the calcite in those deposits.

The depth at which optical calcite is deposited is probably nowhere very great. In fact, the calcite may be deposited almost at the surface, as in the Bacadéhuachic (4) and Oputo (10) districts in eastern Sonora, where the veins are in only slightly eroded late Tertiary and Quaternary valley fill and where they may have been deposited within 20 or 30 meters of the surface. At other places it was deposited at much greater depth, but it is doubtful whether usable calcite is deposited at a depth much greater than 500 or 600 meters. The vertical range of usable material undoubtedly varies from one area to another. In southwestern Chihuahua it is conclusively at least 200 meters and may be greater, but in general the range of commercial deposits probably does not greatly exceed 100 meters. Veins formed at moderate to great depth are generally either completely filled with calcite or contain many other minerals besides calcite; and the calcite in them is not likly to be of optical quality. Because of the shallowness of the deposits, most of those formed in geologically ancient times have been removed by erosion.

The source of the water from which the calcite is deposited may be either magmatic or meteoric, possibly both. The calcium is probably derived principally if not entirely from the rocks in the walls of the fissures. The carbon dioxide is probably of magmatic origin although it could be derived in part from the wall rocks. The apparent close relation between commercial deposits and areas of geologically recent volcanic activity can be explained by the fact that faults and deep fissures in those areas commonly afford channel ways for the escape of water and carbon dioxide. This carbon dioxide is released from small bodies of magma crystallizing at a relatively shallow depth below the surface. Optical calcite undoubtedly is forming at the present time

\footnotetext{
• Hughes, H. H., Iceland spar and optical fluorite: U. S. Bur. Mines Inf. Circ. 6468R, p. 9, February 1941.
}

10 Kelley, V. C., Iceland spar in New Mexico: Am. Mineralogist, vol. 25, p..362, 1940. 
in the throats of some hot springs in such areas. Faults and fissures in more stable areas have no connection with bodies of magma; accordingly, commercial deposits are not likely to be found there. Deposits that are in lava flows and are unrelated to faults were probably formed during the hydrothermal stage of activity that followed the extrusion and accompanied the cooling of the lava. The carbon dioxide was probably released by the lava, the water derived in part from the lava but largely from the surface, and the calcium leached from the lava by the hot carbonated water. It is expected that where the water has a high concentration of silica, which apparently is common, the calcite will be cloudy. Hence deposits in or a short distance above basic rocks are likely to contain clearer calcite than those in or above siliceous rocks.

\section{METHODS OF MINING, CLEAVING, AND SELECTING USABLE CALCITE}

Optical calcite is necessarily mined on a small scale; moreover, most operations are performed by hand. Because of the relatively fragile nature of the crystals, explosives must be used sparingly, if at all, and only with extreme caution. Methods of mining vary from one deposit to another, depending upon the size of the deposit and the toughness of the wall rock. Very small deposits in weathered rock can be worked best with wedge, maul, bar, pick, and shovel, but larger deposits and those in tough or hard rock require the use of explosives as well. A cavity filled with debris and wide enough to permit working in it can be emptied gradually by loosening the debris with a bar or pick, being careful always to probe for any loose crystals that might be scattered through the dirt. Where usable crystals remain on the walls, they can be broken off at the base with wedge and maul and removed one by one. If a filled cavity is too narrow to permit working in it, its width can be increased by removing a little of the footwall, after which the crystals on the hanging wall can be reached. Since usable crystals may remain on the footwall, the layer of crystals should be carefully wedged off piece by piece. This method of hand mining is more or less well known and has long been practised by the Mexican "gambusino" in mining deposits of other minerals.

Open cavities are worked much more easily than those filled with debris, for the danger of fracturing a usable crystal by inadvertently prodding it with a pick or bar is not so great. Where the cavity is not wide enough to permit entry, the footwall must be removed. Frequently, however, it is wide enough to permit recovery of possible usable crystals just ahead of removal of the wall itself, in which event the wall can be removed with less care. Where convenient or necessary to use explosives, half a stick of dynamite, or less if possible, can 
be used to loosen the wall rock by placing it at least half a meter back of the layer of crystals. The loosened blocks of rock and layer of crystals can then be removed with a wedge or bar. Almost invariably it is best to leave the layer of calcite on the hanging wall intact. It is commonly believed that the best calcite occurs scattered in the debris filling a cavity, but such a belief is a fallacy based on observation of conditions near the surface, where cavities in the veins have generally been filled with debris brought in by water draining from the surface. Cavities not filled with debris may contain crystals just as good as those in any other cavity; as a matter of fact, all good crystals were originally deposited in such cavities.

The miner should be cautioned particularly not to pry against the usable part of a crystal, for such pressure invariably produces cleavage fractures and may produce twinning lamellae; nor should he tap or hit a crystal in order to break it from the wall, for the crystal might break far above its base, through the usable portion. Contrary to general opinion, crystals free from internal strain and from incipient cleavage fractures are surprisingly resistant to shock. The fractures seen in most crystals were not produced by rough handling, as commonly believed, but were produced by natural causes and were there when the crystal was in place in the vein. That natural fractures are very common and that they generally are not due to poor mining and rough handling cannot be overemphasized, for much unnecessary and unprofitable exploratory work has been done because of failure to recognize these facts. An experienced observer can generally determine whether fractures are natural or artificial: in a crystal with artificial fractures usually some of the fractures are open enough to show interference colors (p. 135), but crystals with natural fractures rarely show such colors; when they do, the fracture surfaces show the solvent effect of ground water.

Mining a vein completely filled with calcite presents a greater problem, but as few such veins contain usable calcite the miner will ordinarily not be faced with the problem. Should usable calcite occur in a solid vein, however, the best method of attack would be to start in the footwall and gradually wedge the calcite down from the hanging wall. It is believed that small remnants of once larger cavities generally will be discovered during mining of such a vein and that the usable crystals will be found facing such cavities.

To cleave, select, and judge the quality of calcite roughly, a basic knowledge of its physical properties is needed, the common defects should be recognized, and the specifications given by the buyer should be known. Almost anyone can acquire the ability, through a little practice, to make a rough selection of suboptical calcite in the field, 
but much more experience is needed to select high-grade optical calcite, though this also can be done with sufficient practice. Because calcite cleaves readily in three directions, crystals are trimmed by cleaving off the waste: For this purpose a cold chisel with a long tapered edge and a hammer are used. The edge of the chisel should be kept sharp with a file or stone. For cleaving small crystals the chisel should be about a centimeter wide and 15 centimeters long, and the hammer should weigh about half a pound, but for cleaving crystals weighing more than 45 pounds the chisel should be 3 centimeters or more wide and the hammer should weigh $2 \frac{1}{4}$ pounds or more. The chisel and hammer used should be chosen according to the size of the crystals.

The crystal to be cleaved can be placed on any more or less rigid support, though a resilient one that will conform somewhat to the shape of the crystal is best, such as a bag filled with sand or earth. Also the crystal can be placed between the knees, on the ground, or on a thick plank. It should then be rotated until one direction of cleavage is approximately vertical. This position can be determined easily by inspection, if the crystal shows cleavage fractures; if not it can be determined by having well in mind the drawings in figures 8 to 15 . With one cleavage direction nearly vertical, the chisel is placed against the crystal vertically, in such a way that the edge is precisely parallel to the cleavage, and given a sharp firm blow with the hammer. If done properly, the crystal will split with ease and the fracture face will be a nearly perfect plane. If the edge of the chisel is not parallel to the cleavage, the crystal may not split and, instead, abundant incipient fractures may be produced.

Since cleaving with chisel and hammer is a time-consuming method, rough trimming can be done with the hammer or the chisel alone. A small prospector's pick, the point of which has been fashioned into a chisel edge or a narrow rectangular head, may be used to trim off the easily recognized waste. The hammer is then used much as the chisel, hitting the crystal, which is held in the hand, in such a way that the chisel edge, or the long edge of the rectangular head, strikes parallel to one of the directions of cleavage. When the chisel is used alone, the crystal is likewise held in the hand and struck in the same manner. Both these methods are fast though inaccurate, and generally the operator must practice considerably before results are satisfactory. Final close trimming should always be done with chisel and hammer together.

Having the specifications well in mind, defects should be searched for and trimmed off in such a way that the smallest amount of usable material is destroyed. Here the judgment of the cleaver plays an 
important role, and one person might be able to obtain a usable piece from a crystal while another might not. For some purposes it is not necessary to remove all defects. However, trimmed pieces with incipient cleavage fractures in the corners are more likely to be destroyed by shock and temperature changes than those having none. When trimmed clacite is packed for shipment, it should be cushioned sufficiently to prevent the pieces from coming in contact with one another or with any other hard object. Anyone who has mined and cleaved calcite should have no difficulty in judging how to pack it.

\section{SUGGESTIONS FOR PROSPECTING}

The parts of Mexico in which deposits of optical calcite are most likely to be found are: the southern half of Baja California, the eastern half of Sonora and Sinaloa, most or all of Chihuahua, Durango, Zacatecas, Nayarit, Jalisco, Guanajuato, Colima, Michoacán, México, Puebla, and Tlaxcala, the northern part of Guerrero, and the western parts of Hidalgo, Querétaro, and San Luis Potosí。 The bedrock in the greater part of each of the States named is volcanic, and prospecting should be done particularly in those parts covered by volcanic rock. A search for optical calcite in metalliferous veins seems virtually hopeless; instead, the search should be confined to veins containing no minerals other than calcite. Unless small clear pieces of calcite are found in the float on the surface, there is little object in exposing the vein. Where the float is of densely clouded calcite no optical calcite is likely to occur nearby, but where small clear pieces are found the vein should be exposed to a depth of about a meter. If no usable calcite is found at that depth, the prospector should look elsewhere.

If the outcrop of a vein can be followed, particular attention should be paid to a change in strike, the junction with the main vein of a cross or branch vein, the vicinity of a central cavity, or a swelling in the vein. Sometimes the position of a cavity can be located approximately by the presence in the float of pieces with well-formed crystal faces. Many cavities near the surface are filled with soil and debris, in which loose usable crystals broken from the walls may be scattered. Extreme care should be used in exploring such a cavity filled with debris, so that good crystals are not broken. A large cavity along a vein may be open, especially where erosion is rapid, and this cavity can be entered and explored just as a cavern in limestone. If no usable crystals are found among those on the walls of the cavity, exploration' in the floor will probably not be profitable. It should be recognized, unless proved contrary by experience in a particular deposit or area, that any appreciable amount of dead exploratory work underground will be unprofitable. 


\section{MARKETING OF MEXICAN OPTICAL CALCITE}

Virtually all optical calcite produced in Mexico has been exported to the United States. During 1943 and 1944 all but a few hundred pounds of this calcite was purchased by the Polaroid Corp. from an agency in Douglas, Ariz. Before 1944, prices had been erratic, butin February of that year they were stabilized under a planned procurement program that was then put into effect and that continued until Novmber 15 of the same year. Under this program all calcite selected in the field by a representative of the procurement agency, or accepted by the agency in Douglas, Ariz., was paid for at the time of selection, at the rate of $\$ 4$ a pound, and all transportation and other expenses subsequent to the time of purchase were paid for by the buyer. Those who sold calcite directly to the company were paid $\$ 7.50$ a pound for material judged usable by the company in their laboratories, the seller paying all expenses to the factory.

The purchasers realized that some calcite might be destroyed or thrown away in the field by close trimming or selection and that some might be injured during shipment; accordingly, the price paid in the field was set much lower than that paid at the factory-at $\$ 4$ a pound instead of $\$ 7.50$. Thus the field buyer could select with latitude and include all doubtful material, insuring that nothing usable would be discarded. It was hoped that an average of at least 65 percent of the field-selected material would be usable when it reached the factory, but actually only 52 percent of nearly 10,000 pounds purchased on field selection during 1944 was usable. Consequently, the average cost per usable pound of material purchased at the mines was actually $\$ 7.70$ a pound, a cost somewhat higher than the price paid for calcite sent directly to the factory. This has not been recognized nor generally known by the producers, many of whom have believed that all the calcite selected in the field was usable.

It was recognized by the purchasers that high-grade optical calcite generally could not be selected and judged finally in the field, and accordingly it was arranged that all shipments to the Polaroid Corp. would be inspected for material of high grade, which was turned over to the Bausch \& Lomb Optical Co., who purchased such material at prices ranging from $\$ 5$ to $\$ 40$ a pound, depending upon the size and the quality of the pieces. Producers were paid an extra amount for such material, although in a few instances where poor field selection resulted in a loss to the purchaser no extra payments were made.

A few small lots of high-grade and suboptical calcite were sold to others from time to time, at prices similar to those already cited, and a few hundred pounds of well-formed crystals and cleavage rhombohedrons of suboptical calcite were sold at somewhat lower prices to 
mineral collectors, mineral dealers, and museums. Of the material collected by the writer for study and for the National Museums of Mexico and the United States, a part was donated and the rest was purchased at low prices.

\section{PRODUCTION AND RESERVES}

So far as known, no optical calcite was produced in Mexico before 1942. From then until February 1944, when the Polaroid Corp. put its procurement program into effect, about 47 pounds of high-grade optical calcite and $695^{3 / 4}$ pounds of suboptical calcite were produced. Production from February 1 to November 15, 1944, when the procurement program terminated, amounted to 113 pounds of high-grade optical calcite and 10,878 1/2 pounds of suboptical calcite. Production up to the end of November 1944 is given in the following table, in which the production during 1944 is given by months.

Production of optical calcite in Mexico to end of November 1944

\begin{tabular}{|c|c|c|c|c|c|c|}
\hline \multirow{3}{*}{ Period } & \multicolumn{5}{|c|}{ Suboptical calcite 1} & \multirow{3}{*}{$\begin{array}{l}\text { High- } \\
\text { grade } \\
\text { optical } \\
\text { calcite; } \\
\text { usable }\end{array}$} \\
\hline & \multicolumn{3}{|c|}{$\begin{array}{c}\text { Purchased on basis of field } \\
\text { selection }\end{array}$} & \multirow{2}{*}{$\begin{array}{c}\text { Purchased } \\
\text { on basis of } \\
\text { laboratory } \\
\text { selection; } \\
\text { usable }\end{array}$} & \multirow{2}{*}{$\begin{array}{l}\text { Total } \\
\text { usable }\end{array}$} & \\
\hline & Rejected & Usable & Usable & & & \\
\hline Before Feburary 1944 & ${ }_{0}^{\text {Pounds }}$ & ${ }_{0}^{\text {Pounds }}$ & Percent & $\begin{array}{l}\text { Pounds } \\
6953 / 4\end{array}$ & $\begin{array}{c}\text { Pounds } \\
6953 / 4\end{array}$ & $\begin{array}{c}\text { Pounds } \\
47\end{array}$ \\
\hline $\begin{array}{l}\text { February }{ }^{2} \quad 1944 \\
\text { March } \\
\text { A pri1 } \\
\text { May } \\
\text { June-1 } \\
\text { July } \\
\text { August } \\
\text { September } \\
\text { October } \\
\text { November.... }\end{array}$ & $\begin{array}{r}1363 / 4 \\
821 / 4 \\
5934 \\
2023 / 4 \\
772 \\
1,2121 / 2 \\
2831 / 4 \\
1,011 \\
9401 / 4 \\
0\end{array}$ & $\begin{array}{c}6853 / 4 \\
219 \\
309 \\
5553 / 4 \\
71415 \\
8353 / 4 \\
3411 / 2 \\
5331 / 4 \\
877 \\
0\end{array}$ & $\begin{array}{l}83 \\
73 \\
84 \\
74 \\
48 \\
41 \\
55 \\
35 \\
48\end{array}$ & $\begin{array}{c}0 \\
0 \\
0 \\
0 \\
11 / 2 \\
1941 / 2 \\
520 \\
1,21434 \\
2,8001 / 2 \\
1,0753 / 4\end{array}$ & $\begin{array}{l}6853 / 4 \\
219 \\
309 \\
5553 / 4 \\
716 \\
1,03014 \\
861 / 2 \\
1,748 \\
3,677162 \\
1,07534\end{array}$ & $\begin{array}{c}0 \\
0 \\
0 \\
8 \\
0 \\
91 / 4 \\
0 \\
181 / 3 \\
771 / 4 \\
0\end{array}$ \\
\hline Total . & $4,7001 / 2$ & 5,071162 & 52 & $6,5023 / 4$ & $11,5741 / 4$ & 160 \\
\hline
\end{tabular}

1 Does not include suboptical calcite purchased at low prices for use as specimens.

2 Based on date shipped from Douglas, Ariz.

Some of the calcite mined early in November 1944 was not sold before the procurement program terminated and was kept on hand for future demand. About 1,400 pounds, of which possibly 1,200 pounds would have been accepted for suboptical use, was on hand in Durango, and nearly 1,000 pounds, of which perhaps 500 pounds would have been usable, was on hand in Chihuahua. The calcite in Chihuahua included some of high-grade optical quality. All production had ceased by November 11, 1944, and no further mining was planned until the demand should be renewed.

Reserves cannot be measured and estimated as in most metalliferous ore deposits, because of the extremely pockety nature of optical 
calcite deposits. The most productive deposit, the La Fe mine near Rodeo, Durango, yielded nearly 6,500 pounds of suboptical calcite, but as it yielded crystals that could be used only for a specific purpose requiring a very special type of finished cut, it cannot be considered in any way characteristic of calcite deposits in general nor can it be used as a basis on which to estimate the reserves of other deposits. With the exception of this deposit, individual deposits have yielded from 1 to 3,500 pounds, but few have yielded more than 200 pounds. When mining ceased, less than half a dozen deposits were being mined profitably, and many had long before been mined out. All deposits where mining was being continued would probably have been mined out within 3 or 4 months if the demand had continued. A continued production would have had to come from deposits newly discovered meanwhile, or as a result of extensive exploratory work underground.

Rather than estimate reserves as such, it seems better to estimate what the production might be at different price levels. To illustrate the difficulty, moreover, of even estimating production at a given price, one needs only to point out that a slight lowering of the requirements for clarity might increase the yield from a given deposit twofold, threefold, or even fourfold. The effect would be much the same as doubling, tripling, or quadrupling the price without lowering the standards. Therefore, the precise standards used late in 1944 by the Bausch \& Lomb Optical Co. for high-grade optical calcite, and by the Polaroid Corp. for suboptical calcite, are used in the following discussions, although it is recognized that, because these standards change from time to time and different buyers have different standards, the estimates may not even be close.

High-grade optical calcite alone could not have been mined profitably in Mexico at the maximum price of $\$ 40$ a pound current in 1944. As a matter of fact, suboptical calcite bore the major share of the cost of mining, and high-grade optical calcite was recovered only as a by product. Naturally, once a deposit is found and opened up, mining can continue profitably until the pocket is worked out, but there would be no profit nor any incentive to search for new deposits. At a price of $\$ 100$ a pound, without a market for suboptical calcite, a production of 100 pounds or so a year might be maintained for several years in northeastern and southwestern Chihuahua and western Durango by discovery from time to time of small pockets at the surface, but it would not be assured. Unless the amount of calcite consumed annually should increase considerably, such a high price would not be upheld, for calcite could probably be obtained more cheaply in other parts of the world.

In order to maintain the production of suboptical calcite over a period of years at 1,000 pounds or so a month, a price of about $\$ 8$ a 
pound, paid on the basis of material accepted at the factory, would have to be upheld. Production probably would vary widely from month to month as deposits with a high yield were either found or mined out. This variation can be illustrated by pointing out that of 50 deposits producing acceptable material at any given time, one could yield 75 percent of the total production. The effect of mining out such a deposit, which could happen almost overnight, is obvious. It is recognized that a few deposits would yield a high profit, relative to the investment, but the great majority of them would barely pay, and many would be mined at a loss. It is true, also, that a single deposit, after it is discovered, might yield 1,000 pounds a month for several months and be mined profitably at a price, let us say, of $\$ 2$ a pound, but knowing the low yield of the majority of deposits, prospectors would not spend their time searching for others. Moreover, when this deposit was mined out, there is no reason to expect that another like it would have been found, for such large deposits are very rare; on the contrary, a reduced amount of exploration because of the low price would make it even less probable. It should be pointed out that the prospecting that led to the discovery of the deposits mined in 1943 and 1944 was done on the mistaken assumption that calcite was worth from $\$ 50$ to more than $\$ 100$ a pound, and that when the actual price was generally known the amount of prospecting was greatly curtailed. There are many localities in which it would be difficult to encourage the miners to resume prospecting unless the prices were several times as high as those current in 1944 .

Only two deposits yielded more than very small profits at an average price of $\$ 7.70$ a pound for material judged usable at the factory, and a great many were mined at a loss. Nevertheless, a price of $\$ 8$ a pound is high enough to assure a continued search for new deposits in the best areas. At a price of $\$ 12$ a pound, through the continued discovery of new deposits a production of 1,500 pounds or more a month might be maintained for several years. Even at this price, however, it is doubtful whether extended underground exploration would lead to the discovery of enough calcite to repay the cost of such exploration. Given enough time for a thorough search south of Durango, production might rise above the figures given, but this is not assured. It. should be pointed out that the prices cited must be received by the actual producer, not by an agent or broker. Moreover, payment should be made in the field, preferably at the time of selection and purchase; if payment is made in the field, a somewhat lower price might be paid, to allow for less rigid selection, with the understanding that a final settlement would be made after examination in the laboratory. 


\section{MINES AND DISTRICTS EXAMINED}

LA FE MINE, RODEO, DURANGo (1) ${ }^{11}$

The La Fe deposit (pl. 30) is 15 kilometers southwest of Rodeo, Durango, a town about 120 kilometers north of Durango City along the gravel highway leading from Durango into Chihuahua. (See pl. 23.) The deposit can be reached from Rodeo either on foot or by horse in less than 4 hours and is accessible throughout the year. It was discovered by José María Arriola, a rancher who lives nearby and was first opened up in March 1944 by $_{*}$ Adolfo, Ignacio, and Guillermo Torrecillas, and Francisco Martos of El Salto, Durango. Actual mining did not begin until June 1944, when the owners contracted to market their calcite through Hugo P. Keller, Jr., of New York City. Mining was carried on until November 11, 1944, when it was discontinued until the demand should be renewed.

The country rock consists of nearly horizontal flows of hard, gray, porphyritic rhyolite. The usable calcite is related to veins of dense, fine-grained, gray calcite, the longest of which crops out for about 500 meters, strikes nearly north, and dips nearly vertically. Other shorter veins similar in character crop out in the vicinity. The veins that yielded usable calcite are branches of the long vein and strike east-northeast; one dips $40^{\circ} \mathrm{SE}$. and the other $5^{\circ} \mathrm{NW}$. The North mine, which yielded most of the usable calcite, was first opened as a pit, but later a short adit was driven to connect with the bottom of the pit and a winze was excavated to a depth of 16 meters. Shortly before mining ceased another adit was begun 12 meters lower, with the plan of connecting with the bottom of the winze, but it had been driven only 25 meters of an estimated 38 meters when mining ceased. The South mine is an irregular adit extending for 25 meters along a nearly horizontal vein. Ten or twelve cuts and pits were excavated to depths of 1 to 3 meters in the area south of the South mine, and one cut, 2.5 meters deep, was made half a kilometer north of the North mine.

The vein in the North mine has a maximum width of 4 meters. Its walls are irregular, and many narrow veinlets branch off into the broken rhyolite walls. The calcite forms an intersecting boxlike mass of thin plates (fig. 15), simulating the boxwork structure in some quartz veins. The largest plates are about 8 centimeters thick and 30 centimeters in diameter, but the thickness of most of them is less than 2 centimeters. The irregular spaces between the crystals are empty and in some instances nearly sealed by the surrounding crystals;

${ }^{11}$ The numbers in parentheses after the names of mines and districts refer to the localities numbered on the map in plate 23 . 
consequently the crystals are perfectly clean and uncorroded. The calcite near the center of the vein is colorless and in part clear, and this vein has furnished virtually all the material sold; the calcite along and near the walls is yellow, poorly crystallized, and generally unusable. In places the center of the vein contains a cavity that has been filled with debris washed in from the surface. Where exposed, the maximum width of the central cavity is nearly 2 meters, and the filling consists of poorly bedded sand, gravel, and soil. Unlike most such fillings, this one did not contain loose crystals of usable calcite, probably because the crystals on the sides of the cavity were interlocked and could not readily break off. To recover usable crystals, the thin cloudy plates were smashed one by one until the larger clear plates were free. This was done by loosening and breaking down a large block of the vein material, in order to permit the plates to be separated, or by working directly in the face exposed. Undoubtedly much calcite was destroyed at first because of inexperience, but later results were generally satisfactory.

The vein in the South mine varies in thickness from 1 to 2 meters. Its structure is similar to that in the North mine and the crystals have much the same shape, but most of them are too cloudy for use. A few thick crystals weighing 35 or 40 pounds were recovered, but as they contained fractures and cavities with liquid and gas they were not usable. The best crystals in the rest of the workings in the area occur in the northernmost pit, although even there the crystals are small, cloudy, and not usable.

Owing to the type of cut (fig. 14B) made by the Polaroid Corp., plates with a clear layer less than a centimeter thick were usable. Consequently, the material from the North mine was well suited for gun sights. Although the deposit yielded only suboptical calcite, its production was phenomenal. From June 1944 until the middle of the following November some 5,300 pounds were sold; and about 1,200 pounds of the same type of material was on hand after purchases ceased; virtually all of it came from the North mine, the South mine having yielded only about 25 pounds. Nowhere else has such a small mine yielded so much. Although the best part of the pocket was mined out, some usable calcite was still in sight when mining ceased, and mining probably could have been continued for several months with profit. Should mining be resumed, the lower adit in the North mine should be driven to connect with the winze. The high productivity of the best pockets suggests that extensive exploration for others; both on the surface and underground, might be profitable. The chance of finding another pocket equal to that in the North mine is not good but should be recognized. 


\section{ARÉPONÁPUCHIC DISTRICT, CHIHUAHUA (2)}

The calcite deposits in the west wall of the canyon of the Río Urique near Areponápuchic, a small settlement in southwestern Chihuahua, make up the Areponápuchic district (pl. 27). The settlement is 53 kilometers by road south of Creel, the end of railroad lines from Ciudad Juárez and Chihuahua City, and is reached from Creel by truck in about 3 hours when the road is in its best condition. The road from Creel passes through Pito Real and Areponápuchic following the grade of a railroad under construction to connect with the west coast. Beyond Areponápuchic the road branches, one branch continuing to Monterde and the other to Cuiteco. This road can be traveled by truck throughout the year except during the summer after very heavy rainstorms, but the section from Creel north to Cuauhtémoc is frequently impassable during the summer and is at best very bad. Although calcite veins have been explored in many places in the district, only a few have been mined. Of the deposits mined, only the EI Porvenir, La Aurora, and La Flor de Esperanza were commercial, and the El Caimán, La Perla, and Extensión de La Perla, although yielding a few pounds, were unprofitable. Of the rest of the deposits explored but not shown on the map (pl. 27), only one was commercial.

The canyon of the Río Urique ranges in depth from 1,000 to 1,600 meters and exposes an excellent section of the most common rocks in southwestern Chihuahua. The lower third or fourth of the canyon wall consists of moderately basic volcanic rocks, principally flows, tuffs, and breccias of andesitic composition. The upper part consists of intermediate and acidic volcanic rocks, mainly flows and pyroclastics of latitic and rhyolitic composition. The uppermost rocks are generally part of a group of flows of porphyritic gray rhyolite, similar in appearance to the country rock at the $\mathrm{La} \mathrm{Fe}$ deposit in central Durango. The andesitic rocks' in the lower part of the canyon wall may be either late Cretaceous or early Tertiary, and the uppermost flows of rhyolite are probably early Tertiary. ${ }^{12}$ Although the upper rocks throughout the region commonly dip less than $5^{\circ}$, locally the dip is as great as $20^{\circ}$. The higher local dips are apparently caused in most places by accumulation on inclined erosion surfaces. Normal faults are common though not abundant in the region, and generally they trend northwest and have dips steeper than $65^{\circ}$; displacements along them range from less than a meter to 300 meters or more. The calcite occurs in certain parts of these faults. Fissures with calcite occur at all levels in the canyon wall, but the commercial deposits occur only in the upper half, at elevations ranging from 1,500 to 1,900 meters above sea level, in flows and breccia of latite and rhyolite.

\footnotetext{
12 King, R. E., Geological reconnaissance in northern Sierra Madre Occidental of Mexico: Geol. Soc. America Bull., vol. 50, pp. 1680 and 1686. 1939.
} 


\section{el porvenir deposit}

The EI Porvenir deposit is 350 meters below the rim of the Urique canyon (pl. 27) and is reached from Areponápuchic by foot in about. an hour and a half. It was discovered in the fall of 1943 by Francisco. Batista of Areponápuchic, and mining was begun in October 1943 on the recommendation of E. M. Stanton of Douglas, Ariz., and C. R. King of Chihuahua City. Shortly afterward an association was. formed, headed by Martín B. Nesbitt of Chihuahua City and Carlos. Silva of Urique, which with Sr. Batista and others directed mining: and exploration of the El Porvenir deposit and most of the other deposits throughout the region. The El Porvenir continued to be mined until October 27, 1944, when the mine was closed and the final shipment made.

The El Porvenir vein has a pronounced bend where the commercial: deposit occurs (pls. $24 A, 25$ ), and in this section its strike is $\mathrm{N}$. $20^{\circ}-60^{\circ} \mathrm{W}$. and its $\operatorname{dip} 65^{\circ}-75^{\circ} \mathrm{NE}$. Although it crops out for more than 350 meters along its strike, connected exploratory workings have a length of only 50 meters and a vertical range of about the same. amount. The deposit was first opened up at the position of the main. adit (pl. 26), where the width of the zone containing calcite is 7 meters. In both directions from there the width gradually decreases to a few centimeters. The footwall is a well-marked fault, along which. displacement may have been 2 or 3 meters, but there is no well-defined single hanging wall; instead, the rock in the hanging wall is broken by ramifying fissures containing calcite.

Calcite occurs only along some parts of the fault fissure. Wherethe fissure is narrow the filling is generally solid, and where it is wide the filling has a central cavity. Most of the cavities exposed in the mine were open to surface drainage, and although they were not later filled with debris the crystals in them are either partly dissolved or. coated with mud and secondary lime. A few cavities were sealed from surface drainage and contained clean, uncorroded crystals. The. large cavities are connected throughout the workings and can be seen to extend even beyond the limits of mining. Most of the cavities. are less than half a meter wide, but one large cavity in the uppermost. adit is about 3 meters wide. The first calcite deposited is yellow and. contains black cloudy layers; the last deposited is colorless and contains faint white cloudy layers. Most of the crystals have a babit. similar to crystal $E$ in figure 14 or to the arrowhead twin ("corazon") shown in figure 12. Twinning lamellae and cloudy layers are abundant. and fractures are common. Although a few crystals weighed more than 25 pounds, most of them weighed less than one pound.

Most of the usable calcite was mined from a large cavity near theentrance of the main adit, and smaller quantities were obtained from. 
large cavities above there. Very little was found in the lower adit and even less below. Adit $e$, in plate 3 , exposes a narrow vein generally filled with calcite, which is consequently not usable, and where the vein does have a central cavity the crystals are too small for use. Adit $f$, in the same plate, exposes a wider vein with a cavity filled with debris. Most of the crystals in this vein are too small for use, and those that are large enough generally have clouds or cavities containing water, although a few pounds of usable material were recovered.

The El Porvenir is the largest calcite mine in Mexico, and it had the longest period of continuous operation. During the year that it was mined it yielded no high-grade optical calcite, but it yielded nearly 3,600 pounds of suboptical material, far more than any other mine except the La Fe. As a matter of fact, these two mines yielded 75 percent of the total production in Mexico. During the last 2 months of operation, however, barely enough usable material was recovered to repay the cost of mining, and it was generally understood that even if the demand had continued the mine would have closed. Possibly there is more usable calcite above adit $a$, and there is a chance that some might be found by extending adit $e$. However, there is no good reason to expect that further underground exploration would be profitable, for although other pockets containing usable calcite might be found through such exploration, the cost of reaching them might be prohibitive.

\section{LA AURORA DEPOSIT}

The La Aurora deposit is about 600 meters below the rim of the Urique canyon (pl. 27) and is reached from Areponápuchic by foot in about 4 hours, or by horse over another trail in about 5 hours. It was discovered in the spring of 1944 and operated by Sres. Nesbitt, Silva, and associates until mining ceased on October 27 in the following fall. The vein crops out discontinuously for nearly a kilometer along the wall of a deep canyon tributary to the Urique. It strikes northwest and dips about $75^{\circ} \mathrm{NE}$., occuping a fault whose displacement though not determined with accuracy obviously is not great. Although the vein was prospected at intervals along its length, commercial deposits were found in only two short sections. (See pl. 26.) One section is along a slight bend in the vein, near the top of a steep spur, and the other is on a steep hillside where the vein divides into two parts. The length of the higher section is 130 meters and that of the lower, 25 meters; the vertical range of mining is 20 meters.

Generally both the footwall and the hanging wall are well defined. The zone between them averages a meter in width in the higher sec. tion and has a maximum width of about 5 meters in the lower one.

$789679-48-4$ 
The material between the walls consists of breccia and calcite in different proportions. Above, where most of the usable calcite was found, breccia is nearly absent and the zone is occupied by a calcite vein with debris-filled central cavities. Most of the usable crystals were found firmly embedded in this debris. Below, cavities occur also but are not filled with debris, and usable crystals are recovered by breaking them from the walls. The common habit of the crystals is a simple scalenohedron. Some small twin crystals were found in the lower section. The twins are of the same type as those at Areponápuchic, but they are shaped like a flat shaft with a barb on the end rather than like an arrowhead.

Despite the fact that the La Aurora deposit was mined by a few men for a few months only, its yield was much better than average. It produced $26 \%$ pounds of high-grade optical calcite and about 450 pounds of suboptical calcite. Work had been halted in the lower adits some time before all mining ceased, as it did not pay, but the yield from the upper section was at its maximum when work had to be stopped. If mining should be resumed, adit $k$, shown in plate 26, should be extended beneath adit $c$. If the yield is satisfactory there, another adit might be driven 10 meters below adit $k$. It is doubtful whether further mining in the lower adits would pay, although more might be done if work above were profitable. A closer inspection of the outcrops should be made.

\section{LA FLOR DE ESPERANZA DEPOSTT}

The La Flor de Esperanza deposit is about 300 meters below the rim of the Urique canyon (pl. 27) and can be reached from Areponápuchic by foot in an hour and a quarter. The deposit was discovered by Jose Marchimiak, who lives on a small ranch on the upland above the deposit, and was operated by him and the Nesbitt group. Mining was begun in June 1944, and was discontinued the following September because of the low recovery of usable calcite. The veins crop out on a steep hillside (pl. 31), but because of their narrowness they are difficult to find and cannot be traced for more than about 50 meters. The deposit consists of two veins about 5 meters apart, striking northnorthwest and dipping $70^{\circ} \mathrm{SW}$. Both veins occupy faults. Inasmuch as the rock in one wall of the east fault is light-brown breccia and that in the other is light-gray breccia, the displacement along this fault is presumed, on the basis of surface outcrops, to be more than 10 meters, but it may have been less along the west fault, where both walls are of brown breccia.

As shown in plate 31 , mining was done principally in one adit along the west vein, from which a short crosscut was driven to the east vein, and inclined shafts (shown in pl. 31) were sunk on both veins. The 
vein in the west fault is half a meter wide and composed of calcite and breccia. Although narrow cavities are exposed, the crystals along their walls are too small for use. The east vein is somewhat wider and has cavities almost half a meter wide, some of which extend beyond the workings: Most of the crystals are arrowhead twins, like that shown in figure 12. Since these crystals have to be very large to be thick enough to yield usable calcite, the production was consequently small. Less than 40 pounds of usable suboptical calcite was recovered, and no high-grade optical material was found. The well-formed crystals might be mined profitably for disposal to mineral dealers and collectors.

\section{EL CATMÉN DEPOSIT}

The El Caiman deposit is about 300 meters below the rim of the Urique canyon (pl. 27) and is reached from Areponápuchic by foot in about an hour and a half. The deposit was discovered soon after mining began on the El Porvenir vein, but work was halted in May 1944 because of the low recovery of usable material. The vein (pl. 27) occupies a fault striking northwest and dipping $75^{\circ} \mathrm{SW}$., along which the displacement was probably somewhat more than 30 meters. The El Porvenir fault is apparently a branch of the El Caiman, which in turn seems to be an extension of the La Perla. Although the fault is a long one (pl. 27), calcite apparently occupies only certain sections of it.

Exploratory workings were made at three places along the main fault, and another was made on a short branch fault. The largest (shaft A in pl. 27) is an irregularly inclined shaft 16 meters deep. Generally the vein is less than a meter wide and consists of breccia and calcite. The workings expose cavities a few centimeters in width whose walls are lined with partly dissolved, long thin scalenohedral crystals and arrowhead twins. Because of the thinness of the crystals, only a few pounds of usable suboptical calcite was recovered.

\section{Deposits along the la Perla. VeIN}

The main La Perla deposit (pl: 27) is reached from Areponápuchic by foot or horse in an hour and three-quarters. It is about 400 meters below the rim of the canyon. The deposit was discovered early. in 1944 by the Nesbitt group and explored until May of the same year, when it was decided that it could not be mined profitably. The vein is apparently along the same fault fissure occupied by the El Caimán vein. The fault continues north and joins another fault that extends northward a kilometer and a half to the upland. The length of the La Perla section of the fault is nearly a kilometer. Like the El Caimán vein, the La Perla strikes northwest, but the dip is $75^{\circ} \mathrm{NE}$. instead of SW. An irregular excavation (pl. 32) extends about 10 
meters along the vein and exposes a generally tight zone of calcite and breccia averaging a meter in width. Narrow cavities containing crystals like those in the El Porvenir vein are exposed, but most of the crystals are too small for use. A few pounds of suboptical calcite was produced, but it was not enough to repay exploration costs.

Half a kilometer south of the main deposit and about 50 meters higher an adit was driven $9 \frac{1}{2}$ meters along the same fault. The vein there has a maximum width of half a meter and dips $75^{\circ} \mathrm{NE}$. It is generally filled with calcite and breccia, and where any openings occur, the crystals in the walls have a habit similar to those in the El Porvenir vein, but they are too small for use. A few other pits nearby expose the same type of calcite. Work on this deposit was begun late in the summer of 1944, when it appeared that the El Porvenir mine would soon have to be abandoned. No usable calcite was recovered.

\section{OTHER DEPOSITS}

A strong vein that is $2 \frac{1}{2}$ hours by horse southeast of Areponapuchic and about 600 meters below the rim of the Urique canyon was explored at five or six places during the spring of 1944. The vein crops out for nearly a kilometer and is as much as 2 meters wide in places. It occupies a nearly vertical fault striking northwest. Generally it consists of a solid mass of calcite and breccia, but at two places, near the northwest end and highest part of the outcrop, cavities with long narrow scalenohedral crystals were found. Two adits 4 or 5 meters long were driven there, but less than 5 pounds of usable calcite was recovered. As mining was unprofitable, it was soon discontinued.

A deposit in the Urique canyon east of Huirióchic, a small ranch a few kilometers south of Areponápuchic, was discovered and mined early in the fall of 1944, but as it was not known to the writer during his last visit to the district, it was not examined. The deposit yielded about 35 pounds of suboptical calcite.

\section{EL MURCIÉlago DISTRICT, MANUEL BENAVIDES, CHIHUAHUA (3)}

The El Murciélago district (pl. 28) is within the boundaries of the El Murciólngo ranch, in the municipality of Manuel Benavides, Chihuahua. It is about 50 kilometers by road southeast of the town of Manuel Benavides, in the northeastern corner of the State. The district can be reached directly by truck from Chihuahua City or Ojinaga, at the border; or from El Chapo, the closest railroad station on the line from Cbibuahua City of Ojinaga. The road from El Chapo passes through the town of Manuel Benavides. All the roads are bad throughout the summer and impassable after heavy rains, particularly the section between El Chapo and Chihuahua City, but they are easily 
traveled by truck during the rest of the year. The least accessible deposit in the district is less than an hour on foot from the road.

Calcite was found in the district early in the spring of 1944, and mining continued until the middle of the following November. Among those who were most active in exploring and mining the deposits are Jesús and Pedro Rohana of Ojinaga, Guillermo Galindo of Manuel Benavides, Rosendo Estrada of La Mula, General Miguel Comadurán, Jesús Gándara Parra, and Félix Domínguez of Chihuahua City, and the Márquez brothers of the El Parrón ranch which is a few kilometers to the southeast.

The deposits are in some low northwest-trending ridges and uplands known as the Cerro del Coronel and the Sierrita de la Monilla, in the foothills of the Sierra de las Palomas. The district is $4 \frac{3}{4}$ kilometers long and $4 \frac{1}{4}$ kilometers wide, and it may extend even farther. The deposits are at elevations ranging from 1,000 to 1,100 meters above sea level. The hills consist mainly of superposed flows of basalt with an abundance of pecolite, a white fibrous zeolite, but the uppermost flows are of a reddish porphyry, probably latite. All the lavas are probably of Tertiary age. The flows throughout the district dip $15^{\circ}$ SW., and since the uppermost red flows occur at successively lower positions from southwest to northeast, all the flows are presumed to have been tilted along a group of northwest-trending normal faults, as shown in the geologic section in plate 31 . The valleys contain poorly consolidated conglomerate of Quaternary age.

Calcite occurs in fissures and faults in the basalt and, at some places, in the latite, although no usable material was found in the latite. The fissures strike northwest and generally dip $70^{\circ}$ or $80^{\circ} \mathrm{NE}$. Although they probably continue much farther than they can be traced on the surface, the sections containing calcite are discontinuous and generally short. The largest continuous vein is about 800 meters long, and some of the small ones are less than 50 meters long. Although the calcite-bearing fissures are parallel to the major faults in the district, no commercial deposit was found in what could be clearly interpreted as a major fault. Most of the veins are only a few centimeters wide and contain usable calcite only in swellings that have central cavities.

There are probably more than 300 individual shafts and pits in the district. The veins were explored principally by shafts, of which the deepest, about 9 meters deep, is along an open cavity in the north end of the district. Four or five other shafts range from 6 to 8 meters in depth, and the rest average about 2 meters. The usable crystals are generally found embedded in debris, which is cemented with caliche that has filled cavities in the swellings in the veins. In a few places 
where mining was deep enough to reach cavities that were nearly sealed from surface drainage, usable crystals were found on the walls. Very few crystals are well formed. The most common habit is a short thick scalenohedron with some rhombohedral faces. Some of the veins a kilometer north of the Arroyo de la Monilla (pl. 28) have a boxwork structure somewhat like that in the La Fe deposit in Durango (p. 153). A few usable basal plates have been recovered, but most of them are too cloudy for use. Although the calcite mined from the veins throughout the district is pale yellow, all that was found as float is colorless, indicating that long exposure to sunlight destroys the color. Individual crystals weighing as much as 100 pounds have been found. Fractures and lamellar twinning are very common in all the crystals in the district.

Up.to the middle of October 1944, when the last shipment under the procurement program was made, the district had produced about 1,500 pounds of suboptical calcite and nearly 50 pounds of high-grade optical calcite, a part of which was sold in Chicago, Ill. Late in November 1944, after mining had ceased, about 1,000 pounds of material was on hand, of which possibly 500 pounds might have been usable; this part included some that was of high quality. The largest yield of any single deposit was nearly 500 pounds, which came from a shaft on the long vein that crosses the Arroyo de la Monilla, in the section of the vein south of the arroyo. All the best calcite available in the workings was removed before mining ceased, and consequently exploratory work would have to be done before production could be resumed. Undoubtedly many more veins are present, as yet undiscovered, and the known veins can be searched further for any deposits that might have been overlooked.

\section{BACADÉHUACHIC DISTRICT, SONORA (4)}

Calcite veins are scattered over an area 15 kilometers long, from 5 to 20 kilometers north of the town of Bacadéhuachic in the valley of the Río de Bacadéhuachic in eastern Sonora. The town is about 5 hours by horse east of Granados, which is the end of the automobile road from El Tajo, a station on the railroad line between Agua Prieta, at the border, and Nacozari. The deposits are north of Bacadéhuachic and can be reached in 1 to 4 hours by horse from town. In that area veins have been prospected in about 20 separate localities, but the only profitably mined deposit is in the most distant of the localities, near the head of a northeast branch of the main valley, on the El Huerigo ranch. Other veins have been found at a distance of an hour's ride by horse east of town, but have yielded no usable calcite, and still other unproductive deposits were found near Nácori Chico, which is a day by horse southeast of Bacadéhuachic. The deposits 
were first mined in February 1944 ; mining continued until the following August, when the yield of the best deposit became too low for profitable operation. Among those who were most active in mining and exploration are Astolfo Valenzuela, Angel Escalante, Manuel Madrid, Ignacio Córdoba, Cristóbal Valencia, Pedro García, and Abelino Valenzuela, all of Bacadéhuachic.

The deposits are in a broad valley between high mountain ranges trending north-northwest, which are composed of volcanic rocks, chiefly andesite and latite, of late Cretaceous(?) and early Tertiary age. The valley contains thick deposits of poorly consolidated conglomerate composed of debris eroded from the mountains and deposited late in Teritiary time and possibly also early in Quaternary time. The conglomerate apparently once formed gently sloping plains in the valleys, but it has since been faulted, tilted, and eroded, and it is now dissected by many shallow, narrow, steep-sided arroyos. This conglomerate is probably equivalent to what in other parts of Sonora is called the Báucarit formation, a terrestrial valley-and-basin fill that appears to be approximately equivalent to the Gila conglomerate in southern Arizona. ${ }^{13}$ Since the formations over large areas in the ranges west of Bacadéhuachic dip from $10^{\circ}$ to $20^{\circ} \mathrm{W}$., and normal faults parallel to the ranges are readily seen here and there, it is presumed that the ranges were formed by large displacements along normal faults trending north-northwest. The calcite veins occupy fissures more or less parallel to these faults and crop out on the surface of the conglomerate and in the upper parts of the sides of the shallow arroyos that dissect it. Most of the veins are near the sides of the valley not far from the contact between the conglomerate and the volcanic bedrock. As the calcite could not have been deposited before the Baucarit formation was faulted, probably in Pleistocene tim.e, these deposits are more recent than Pliocene and, therefore, the youngest known in Mexico, as far as direct evidence is available.

The only commercial deposit in the district is along one of a group of veins in a northwest-trending zone 300 meters long and 60 to 90 meters wide, at an elevation of about 1,000 meters above sea level. Most of the veins in the zone strike northwest and dip $45^{\circ}$ to $80^{\circ}$ NE., but a few short ones cross them at nearly a right angle. The veins are somewhat irregular in strike and dip; and they generally do not crop out for more than 70 meters. As they are covered with a soil mantle, however, they may be much longer than is apparent. Their width varies from a few centimeters to about 2 meters. Exploatory workings from 1 to 2 meters deep have been made in about a dozen places, and, near the bottom of a shallow arroyo, one larger

18 King, R. E., Geological reconnaissance in northern Sierra Madre Occidental of Mexico: Geol. Soc. America Bull., vol. 50, pp. 1681-1692, 1931. 
excavation was made at the intersection of two veins (pl. $24 C$ ). There a northwest-trending vein is exposed to a depth of 3 or 4 meters for a distance of about 25 meters, and a cross vein is opened to a depth of nearly 5 meters for a distance of 6 or 7 meters. At the intersection of the veins is a jumbled mass of calcite and strongly altered conglomerate whose maximum width is about 3 meters. The open cavities exposed are 2 or 3 centimeters wide and have small crystals along their walls, but the largest cavity was filled with calichecemented rubble, embedded in which were abundant broken crystals, some weighing as much as 45 pounds. All the large crystals are twins similar to $E$ in figure 11 , and most of the small ones are twins similar to $G$ in the same figure. Although twinning lamellae and fractures are abundant in the small crystals, the large crystals are generally free from twinning lamellae. Faint cloudy layers are common in all the calcite. One of the largest trimmed pieces weighed 17 pounds, but because of the twinning plane in these crystals, only the largest ones yield usable calcite.

The production from the Bacadéhuachic district was 265\% pounds of usable suboptical calcite, of which all but 2 or 3 pounds came from one deposit. This deposit had been worked out by August 1944, and no others had been found. The chief reason for the poor showing of most of the deposits is the predominance of small-sized twin crystals; single crystals of the same size would yield usable material. Further prospecting might lead to the discovery of other pockets with large crystals, but if no usable calcite is found at the surface, underground exploration would not pay.

\section{PITO REAL DISTRICT, CHIHUAHUA (5)}

Deposits were found during the summer of 1944 in the Urique canyon east of Pito Real, a small settlement about 30 kilometers south of Creel, about half a day by horse from that town, on the road to Areponápuchic in southwestern Chihuahua. As they were not known to the writer at the time of his last visit to that region, they were not examined. The geology of the district is similar to that of the Areponápuchic district (page 155), and presumably the deposits are similar in shape and size to those farther south. The best deposit is said to be near Agua Caliente. The production from there was about 140 pounds of usable material, including about 25 pounds of high-grade optical calcite. Presumably the deposits were not worked out when mining ceased in October 1944.

Some other deposits were explored in the canyon of the Río de Oteros, west of Pito Real, where the geology is like that in the Urique canyon. Although a few pounds of usable calcite was produced, 
the deposits are said not to be commercial. Deposits near Maguarichic, west of Creel, were explored also but did not prove commercial, although a few pounds of usable calcite was produced.

\section{E⿱ PARRón DISTRICT, MANUEL BENAVIDES, CHIHUAHUA (6)}

The El Parron district is on the El Parrón ranch, about 15 kilometers by road southeast of the center of the El Murcielago district (page 160). The deposits were mined principally by the Márquez brothers, who own the ranch. The geology and veins are similar to those in the Murciélago district (page 161) and need no furtber description. The main shaft, which is about 400 meters northwest of the Márquez home, has been sunk to a depth of 7 meters in a large swelling along a vein that strikes $\mathrm{N} .45^{\circ} \mathrm{W}$. A few basal plates occur in a part of the deposit, but the usable crystals are like those in the Murciélago district. Production from the district probably did not exceed 250 pounds of suboptical calcite. Further exploration might lead to the discovery of other commercial deposits in the district.

\section{MONTERDE DISTRICT, CHIHUAHUA (7)}

The mining town of Monterde is about 35 kilometers by road west of Areponápuchic, in southwestern Chihuahua, and can be reached by truck from Creel in about 6 hours when the road is in good condition. It is about 3 hours beyond Areponápuchic over a poor road with some very steep grades. Calcite deposits have been explored west and north of town, but only two, those at Arechuchique and Las 'Trojas, were examined by the writer. The deposits were explored and mined principally under the direction of $\mathrm{L}$. V. Blum of Monterde and C. R. King of Chihuahua City. The search for calcite began in the summer of 1943 , and because of poor recoveries, most of the work had ceased by August 1944. The calcite veins are in the watershed of the Rio de Oteros, which, like the Río Urique, has cut a canyon more than 1,000 meters deep. The geology is similar to that in the Areponápuchis district, except that in places the older rocks stand as monadnocks above the middle and late tertiary lavas, forming hills on the upland like those at Monterde. The calcite veins examined are in the lavas, however, and most of those described to the writer but not examined by him are likewise in the lavas.

The locality known as Arechuchique is in a canyon 600 meters deep, tributary to the Oteros canyon, about 4 hours by horse northeast of Monterde. The veins crop out in latite or rhyolite on steep hillsides and are 200 or 300 meters above the bottom of the canyon. One vein that yielded some usable calcite is from 0.5 to 3 meters wide and crops out for more than 100 meters. At one place along this vein an opening 
just large enough to admit a man leads into a large cavern 10 meters deep and 20 or 25 meters long, with a maximum width of nearly 3 meters. The cavern was a water course at one time, and many of the crystals have been partly dissolved or were completely removed; some are covered with secondary lime, including. stalactites and stalagmites. The cavern floor is covered with fine dirt, which apparently prevented the escape of the water and held it at a nearly stationary level long enough to dissolve in part the calcite below that level. The crystals remaining on the walls, though similar in habit to the single crystals in the El Porvenir vein (fig. $14 \mathrm{E}$ ), are too cloudy or too fractured to be usable. Others found at the surface near the large cavern were usable. Another vein half a kilometer north of this one also contains a large cavern, but as the crystals have layers of dark clouds they are not usable. Still other veins are said to have been found in the area, but none yielded optical calcite.

The locality known as Las Trojas.is about 4 hours by horse northwest of Arechuchique and about 400 meters below the south rim of the Oteros canyon. The main vein occupies a fault that appears to extend for several kilometers along the side of the canyon. The principal workings are on the steep side of a short spur, where some narrow cavities have been opened and explored. There the vein has several narrow branches extending out into the country rock, but the crystals in their cavities are too small for use. In the cavities along the main vein the crystals are large but badly fractured; consequently very few were usable. The crystals seem to be under internal strain, for some of the small cleavage fractures left in trimmed pieces enlarge when the pieces are set aside for a few minutes. Several small pits at intervals along the same vein have yielded nothing better. Veins are said to occur also in the north wall of the Oteros canyon, but none were mined.

The production from the Monterde district amounted to a little more than 100 pounds of suboptical calcite. It is doubtful whether the cost of mining and exploration was repaid by the small amount of usable material recovered. A continued search, however, might lead to the discovery of some better deposits.

SAN ISIDRO DISTRICT, DURANGO. (8)

The San Isidro district is on the Guacamaya ranch, in a deep canyon tributary to that of the Río de las Viborillas in western Durango and eastern Sinaloa. Although the district can be reached from central Durango in 6 or 7 days by horse from the nearest road, it is best reached from Cosalá, Sinaloa, which is at the end of truck roads from Culiacán and La Cruz, the nearest station on the railroad. Culiacán is about 9 hours by auto stage from Cosolá when the road is passable, and about 7 hours from La Cruz when the road is in good condition. During the summer when rains are frequent and heavy, the Río de San Lorenzo is often too high to be forded, and traffic from Culiacán stops. At the same time the Río de las Viborillas is often 
too high to permit reaching the deposits by horse, as the trail follows the bottom of the valley. The trip from Cosala to San Isidro, the settlement nearest the deposits, can be made in a day and a half by horse, and from there the deposits are south about 2 hours by horse, up a canyon tributary to that of the Río de las Viborillas. The deposits were found and explored in January 1944 by Severo Robles of San Isidro and Angel N. Zazueta of Cosalá. Mining began late that spring and continued until early in the following September, when it was halted because of the imminent termination of the procurement program.

The veins are in andesitic rocks of late Cretaceous (?) age underlying early Tertiary(?) latite and rhyolite, which crop out in the upper parts of the canyons and over most of the high plateau farther east. When the district was visited by the writer in February 1944, before mining had begun, only one deposit was seen. There a vein that could be traced on the surface intermittently for nearly a kilometer had been prospected virtually on the side of a cliff. In a cut, 5 meters long, the vein was a meter and a half wide and had an open cavity half a meter wide. Well-formed thick scalenohedral crystals lined both walls. Twinning lamellae and incipient cleavage fractures are common in all the crystals. Crystals weighing 20 or 25 pounds had been found as float on gently sloping ridges and hillsides nearby, it was said, and another vein had been found in a canyon about 4 kilometers east.

Exploration during the spring, after the writer's visit, led to the discovery of other deposits in the region around Cosalá. One of them is near Palo Blancar, Durango, and another is about 4 hours by horse southwest of Santa Ana, Durango; both were explored by Taurino García and Angel Zazueta of Cosalá. Other deposits were found near El Carrizal, about 8 kilometers north of Cosalá, and near La Cantera, about 15 kilometers south of Cosalá. The geology of these deposits was not described to the writer.

The total production from the district was 90 pounds of optical calcite, of which 15 pounds was of high-grade quality. It is doubtful whether mining was profitable at most of the deposits. Further search, however, might lead to the discovery of other commercial deposits.

\section{EL CRISTAL MINE, CUMPAS, SONORA (9) ${ }^{14}$}

The El Cristal mine is $2 \frac{1}{2}$ kilometers by' trail up a narrow canyon leading from the home of Sóstenes Hernández, whose ranch is 18 kilometers by road east of Cumpas in eastern Sonora. The deposit was mined under the direction of E. M. Stanton of Douglas, Ariz.,

14 The El Cristal mine was examined by John H. Wiese and has been described by him in a manuscrip report in the files of the U. S. Geological Survey. 
during 1942 and during the early part of 1943, after which work was discontinued because of the poor yield. The country rock consists of a rectangular block of recrystallized limestone, which strikes northwest and dips vertically, in contact concordantly with metamorphosed volcanic rocks on the northeast side and with soft blue slate on the southwest side. The block is about 20 meters wide and more than 100 meters long. The contacts consist of zones of brecciated rock, which have a maximum width of 10 meters. The brecciation is most intense in the limestone within a meter or two of the contacts and was probably produced both by faulting and by collapse of solution caverns.

Calcite fills openings in the limestone breccia along both contacts of the limestone block; along the slate contact it forms a series of stepwise veins roughly parallel to the contact. Three small open-cuts and six short adits were dug along the southwest slate contact, but only three small pits were dug along the less explored northeast, volcanic-rock contact. The veins are about a half a meter wide and are filled with white calcite, except at a few places where there are cavities. The cavities have a maximum width of a meter and have been partly or almost completely filled with debris, generally cemented with lime or caliche. The crystals along the walls are short thick scalenohedrons containing many twinning lamellae and incipient cleavage fractures. Generally they are pale yellow, but some are colorless. Inclusions and cloudy layers are common.

It is reliably reported that 42 pounds of high-grade optical calcite was recovered from the deposit, most of it probably from the westernmost pit. Although mining was done before suboptical calcite was in demand, apparently there was no calcite of even that quality left in sight, for the writer examined 2 tons of the best material selected from the dumps early in 1944 and found nothing usable. The deposits are apparently not worked out, but the cost of obtaining the usable material would probably be prohibitive if operations were resumed.

\section{OPUTO DISTRICT, SONORA (10)}

The Oputo district is half an hour to an hour by horse east of the town of Oputo in eastern Sonora, on the east side of the Río de Bavispe. The district is west of the mountain range that separates the valley of the Río de Bavispe from that of the Río de Bacadéhauchic. Oputo can be reached by truck from Nacozari, the end of the railroad line from Agua Prieta, in about 5 hours. The deposits were first explored in January 1944 by Antonio E. Samaniego of Oputo. Among those who continued to explore and mine during the months that followed are Ricardo Castillo, Loreto Ríos, Manuel Durazo, Miguel Martínez, and 
Jesús Valenzuela. Mining was discontinued in August 1944 because of the low yield of usable material.

The veins crop out in weakly cemented, andesitic conglomerate of late Tertiary or early Quaternary age, probably the Báucarit formation. The geology, the size and shape of the deposits, and the type of calcite in the veins are similar to those in the Bacadéhuachic district, described on pages 163-164. Most of the veins are near the contact of the conglomerate with the volcanic bedrock on the east side of the valley, but a few are farther away, within half a kilometer of the river; none were found on the west side of the river. Many of the large crystals are twins similar to $\dot{G}$ in figure 11 , but none of the rarer type of twin found at Bacadéhuachic ( $E$ in fig. 11) were seen. Veins were explored to depths of 1 to 2.5 meters at 14 or 15 plaçes in an area extending 3 or 4 kilometers along the front of the mountain range. The poor yield of the deposits is due to the common occurrence of twin crystals and the small size of the single crystals, almost all of which have abundant twinning lamellae, incipient cleavage fractures, or faint cloudy layers.

Production from the district was about 20 pounds of usable suboptical calcite. Much more was spent for mining and exploration than was recovered from the calcite sold. Presumably any other veins found in the area will be similar to those already explored; consequently, there is little reason for further prospecting nearby.

\section{CHINIPAS DISTRICT, CHIHUAHUA (11)}

The Chinipas district, not visited by the writer, is about 80 kilometers west of the Areponápuchic district, in southwestern Chihuahua. Cuiteco, the nearest town accessible by truck, can be reached from Areponápuchic in about 3 hours over a narrow rocky road with very steep grades; from there the trip to the town of Chínipas requires 2 or 3 days by horse. The deposits are said to be at some distance from the town. They were found and explored in the spring of 1944 under the supervision of the Nesbitt group of associates, and mining was discontinued in the following October. The veins are in the walls of canyons tributary to the Oteros and presumably are similar to those in the Monterde and Areponápuchic districts. The production was not reported separately but probably was not greater than 50 pounds of suboptical calcite. Mining was said to have been unprofitable.

EL CALICHE MINE, MAZOCAHUI, SONORA (12) ${ }^{15}$

The El Caliche mine is at the corrals of the La Noria de Lares ranch, on the west bank of the Arroyo de la Junta, near Mazocahui

15 The El Caliche mine was examined by John $\mathrm{H}$. Wiese and has been described by him in a manuscript report in the flles of the U. S. Geological Survey. 
in eastern Sonora. It can be reached by truck from Nacozari or Hermosillo. The road between Nacozari and Ures crosses the Arroyo de la Junta at a point 58 kilometers north of Ures, and from there a dirt road leads 11 kilometers up the arroyo to the mine. The deposit was mined at intervals during 1942 and 1943 by Francisco Contreras of Hermosillo, at the recommendation of E. M. Stanton. The country rock consists of Tertiary andesite flow breccia. The calcite occupies two fissures, 4 meters apart, varying in width from less than a centimeter to half a meter. It extends for 10 meters along one fissure and for 6 meters along the other. Pits have been dug on both to a depth of 7 meters, where the calcite apparently pinches out. The largest crystals recovered were steep modified rhombohedrons weighing 3 to 5 pounds each. Twin crystals are common, and most of the calcite contains inclusions and cloudy layers. It is reliably reported that 5 pounds of high-grade optical calcite was produced, which was not enough to repay the cost of mining.

\section{LA ESMERALDA MINE, GUAGÜEYBO, CHIHUAHUA (13)}

The La Esmeralda mine is in the wall of a narrow steep-sided canyon tributary to the Río Urique, halfway between the villages of Guagüeybo and Cieneguita in southwestern Chihuahua. It can be reached by horse from Areponápuchic in a day and a half. The village of Guagüeybo is across the Urique canyon from Areponápuchic, a trip that can be made in a day by horse, and the deposits are half a day by horse farther to the southeast. The veins were explored in April 1944 by Rosario Mancinas and Francisco Batista, and mining continued at intervals until early in the following October, when it was halted because of the low yield of usable material.

The main vein is about 700 meters below the upland, in flows and breccia of rhyolite and latite similar to those in the Areponápuchic district. It crops out for half a kilometer or more and varies in width from a few centimeters to nearly 5 meters. It strikes northwest, like most of the others in the region and dips at an angle of about $70^{\circ} \mathrm{NE}$. Cuts were made along it at several places and also along three short veins nearby. (See pl. 32.) Most of the mining, however, was done in a large swelling along the main vein, where there is a marked change in dip from $70^{\circ} \mathrm{NE}$. to vertical. Two adits were driven for about 25 meters along the vein and then connected by a raise; a winze was sunk to a depth of 7.5 meters from the end of the lower adit, making the full vertical extent of the connected workings about 20 meters.

The vein consists of a mixture of broken and altered country rock with ramifying veinlets of calcite. Cavities with crystals weighing as much as 25 pounds may be found along parts of the vein; at other 
places the vein is a solid mass of calcite. Twin crystals similar to $E$ and $G$ in figure 11 may be found but are not common. The single crystals are long distorted scalenohedrons, many of which are relatively flat parallel to the vertical (c) axis. Although the crystals are pale yellow and have abundant faint cloudy layers, the main reason for the low yield of usable material is the abundance of liquid-filled cavities near their centers and incipient cleavage fractures in their borders.

About 120 pounds of calcite was sold, but of this amount only 8 or 10 pounds proved usable upon laboratory inspection. The deposit was definitely not commercial. Other veins had been found in the region, but none yielded usable calcite. A further search might be made nearer the top of the canyon.

\section{MAPIMI DISTRICT, DURANGO (14 AND 15)}

Deposits that are 45 and 65 kilometers by road north-northwest of Mapimí, in northeastern Durango, were explored and mined during the spring of 1944. A good highway leads from Mapimí to Torreon, Coahuila, but the road from Mapimí to the deposits is very poor. The most distant deposits can be reached by truck from Mapimí in $3 \frac{1}{2}$ hours when the road is dry. They were explored by Felipe Mireles and Angel Tavera of Torreón, but they yielded nothing usable. The other deposits can be reached from Mapimí in about $2 \frac{1}{2}$ hours when the road is dry. They were explored and mined under the direction of Arnulfo García of Torreon. Although the writer inspected calcite from these deposits he could not reach the deposits themselves because of heavy rains that made the roads impassable.

The most distant deposits are in a group of low hills of latite or rhyolite, at an elevation of about 1,350 meters above sea level. The principal vein strikes $\mathrm{N} .25^{\circ} \mathrm{W}$. and dips $65^{\circ} \mathrm{SW}$. It crops out for more than 50 meters and varies in width from less than half a meter to about 2 meters. Of several small pits along this vein, the largest is 2 meters deep and 2 meters long. There a cavity half a meter wide is exposed, on whose walls are short thick rhombohedral crystals. Because of the abundance of clouds, twinning lamellae, and cleavage fractures, there seemed little chance of obtaining any usable material, and nothing better was seen along the outcrop of the vein. An intensive search in the area might lead to the discovery of other pockets with usable material.

The deposits owned by Arnulfo García, though not examined, are probably in volcanic rocks like those farther north. Of some 10 tons of the best material mined from the veins, less than 10 pounds was found usable. Some of the material undoubtedly was injured during transportation and handling, but even if none of it had been thus 
destroyed mining would not have been profitable. Perhaps other veins yielding a higher percentage of usable calcite might be found by further prospecting in the area,

\section{DISTRICT EAST OF ESQUEDA, SONORA (16)}

Calcite veins were found early in 1944 on the west side of the valley of the Río de Bavispe, east of Esqueda in northeastern Sonora. They were explored under the direction of Ramón Ríos, of Agua Prieta, who discontinued work in April of the same year because of the lack of usable material. All the deposits explored are less than a kilometer from the road between Esqueda and El Tigre and about 25 kilometers east of Esqueda. The bedrock is weakly cemented andesitic conglomerate, probably a part of the Báucarit formation of late Tertiary and early Quaternary age, similar to the conglomerate in the Bacadehuachic and Oputo districts.

Six veins, from half a kilometer to a kilometer east of the contact of the conglomerate with outcrops of the underlying volcanic rocks, were explored by small pits and cuts, the largest of which is 5 meters long, 3 meters wide, and 1.5 meters deep. This cut is along a vein that crops out for nearly 200 meters and that varies in width from a few centimeters to a little more than a meter. The vein strikes northnorthwest and dips nearly vertically. The cut exposes a solid mass of calcite with a narrow horse of conglomerate. Since there is no central cavity, the crystals are in contact with one another and are not well formed, and although single crystals weighing more than 60 pounds occur in the vein their usefulness is destroyed by abundant cleavage fractures and twinning lamellae. Most of the material also contains dense white clouds. The veins and the calcite are much the same at the other places explored, although some small cavities with crystals too small for use were exposed in two or three cuts.

No usable calcite was produced, and there seems to be little chance of finding any nearby. Perhaps a more extensive search, beyond the area prospected, might lead to the discovery of some better veins.

\section{ARIZPE DISTRICT, SONORA (17) 10}

Calcite occurs in short veins with small cavities in a low hill about 2 kilometers west of the town of Arizpe, in northeastern Sonora. Arizpe can be reached by truck from Agua Prieta or Naco, both of which are at the border. The deposit was opened on the recommendation of E. M. Stanton, of Douglas, Ariz., in 1942. The crystals are poorly formed, contain many cloudy layers, and do not yield flawless pieces large enough for optical use. There has been no production from this district.

${ }_{10}$ Examined by John $\mathrm{H}$. Wiese and described by him in a manuscript report in the files of the U. $\mathbf{8 .}$ Geological Survey. 
TARAHUACÁCHIC DISTRICT, SONORA (18) ${ }^{17}$

A calcite-bearing fissure was explored at Tarahuacáchic, in eastern Sonora, during 1943. The vein is along an arroyo about a kilometer east of a point on the highway between Ures and Nacozari that is 5 kilometers north of the town of Baviácora. The country rock is brecciated andesite, probably a flow. The vein occupies a northtrending fissure and crops out, for a total distance of 40 meters, as a group of lenses 25 centimeters wide and 3 meters long. The crystals are generally small and intergrown, but in cavities in the widest parts of the lenses they are somewhat larger and better formed. The best material is exposed in a trench 3 meters long and a meter deep, but none of the crystals are usable because of abundant inclusions and liquid-filled cavities.

\section{GUÁSABAS DISTRICT, SONORA (19)}

Some calcite veins on the east side of the valley of the Río de Bavispe, east of Guásabas in eastern Sonora, were explored early in 1944 under the direction of Cuauhtémoc Montaño of Cumpas, Sonora. The deposits were not examined by the writer, but they were described to him as being similar to those near Oputo (p. 169), a few kilometers farther north. The crystals are much like those from Oputo; they yielded no usable calcite.

\section{CHUHUICHUPA DISTRICT, CHIHUAHOA (20) ${ }^{18}$}

Calcite deposits near Chuhuichupa, in northwestern Chihuahua, were found and explored in the fall of 1943, principally by Carl Farnsworth, of Chuhuichupa and E. M. Stanton, of Douglas, Ariz. After Dr. Stanton's death in November 1943, Mr. Farnsworth continued exploration until the following February, when sufficient work had been done to prove that the deposits would not yield usable calcite. The crystals are said to occur in caverns in limestone. Some of them weigh nearly a ton, but they contain so many incipient cleavage fractures that not a single piece large enough for use could be obtained.

\section{SAHUARIPA DISTRICT, SONORA (21) ${ }^{10}$}

Calcite veins are said to occur a few kilometers north of the town of Sahuaripa, in eastern Sonora. The veins were not examined by the writer nor by Wiese but are said to be in limestone. Specimens brought in for inspection contained dense white clouds and were badly fractured. Presumably there is little chance of finding any usable calcite in the deposits explored.

\footnotetext{
${ }^{17}$ Examined by John H. Wiese and described by him in a manuscript report in the files of the U. $\mathrm{s}^{\text {. }}$ Geological Survey.

18 Described to the writer by O. A. Reese, of Colorado Springs, Colo.

10 Described by John H. Wiese in a manuscript report in the fles of the U. S. Geological Survey.
} $789679-48-5$ 


\section{DISTRICT SOUTH OF LA MULA, CHIHUAHUA (22)}

$\therefore$ A group of calcite veins about 15 kilometers south of La Mula, in notrtheastern Chihuahua, was prospected during June 1944 under the direction of Chaquer Rohana, of Ojinaga, but work was discontinued a month later when it was apparent that the deposits contained no usable calcite. The locality is on the south side of the high ridge south of La Mula and can be reached directly from that town by horse, or more conveniently by driving southeast about 20 kilometers and then riding west-southwest 2 hours by horse. The veins are in a group of Tertiary basalt flows overlying limestone of Cretaceous age. The largest one strikes nearly north and dips steeply, but many of the small ones have widely different strikes. They range in width from about a centimeter to half a meter, and few crop out for as much as 100 meters in length.

Three of the most persistent veins were explored to a depth of a meter and a half. At a few places where central cavities occur the crystals are too small and contain too many cloudy layers for use, although twinning lamellae and cleavage fractures are not abundant. No better calcite was found in any of the other 12 or 15 veins explored. If a cavity could be found in which the crystals were at least 7 centimeters in diameter, the chance of obtaining usable pieces would be good.

Other deposits were found and explored in the hills north of La Mula, but no usable calcite was found.

\section{DISTRICT SOUTH OF MANUEL BENAVIDES, CHIHUAHUA}

Some calcite veins that are about 5 hours by horse south-southwest of Manuel Benavides, in northeastern Chihuahua, were explored in June 1944. The veins are in a broad valley eroded partly in calcareous shale of Cretaceous age and partly in Tertiary basalt flows that overlie the shale and form small hills in the valley. Two veins in one of these small hills of basalt, and others in the shale, were explored' by pits about a meter deep. The veins in the basalt are less than half a meter wide and contain pale-yellow calcite with abundant twinning lamellae and cleavage fractures. Those in the shale are only a few centimeters wide and contain crystals too small for use. Although no usable culcite was obtained, the amount of exploration was not sufficient to prove that none occurs in the district. Prospecting should be confined to the areas in which basalt crops out.

DISTRICT EAST OF MANUEL BENAVIDES, CHIHUAHUA

Calcite veins were found in June 1944 in the hills north of the road leading from Manuel Benavides to the El Murciélago and El Parron districts at a point about 20 kilometers east of Manuel Benavides. 
The veins crop out on the hillside about 100 meters above the bottom of the valley and are in some small masses of monzonite or diorite that intrude Cretaceous beds of limestone and shale. They trend northwest and are nearly vertical. One vein crops out for a length of about 100 meters and has an average width of about 10 centimeters. The largest pit on this vein is a meter and a half deep and exposes poorly formed crystals of colorless, faintly cloudy calcite. No usable calcite was obtained, principally because of the small size of the crystals, and the outcrops indicate that further exploration nearby is not likely to be profitable.

\section{EL FUERTE DISTRICT, SINAOLA (25)}

Calcite veins are said to occur a few hours by horse east of $\mathrm{El}$ Fuerte, in northern Sinaloa. The veins were explored in 1943 at the recommendation of E. M. Stanton. Although the writer did not examine the deposits, crystals shown him by Thomas Smith, of El Fuerte, contained too many twinning lamellae and cleavage fractures to be usable.

\section{SAN JAVIER DISTRICT, SINALOA (26) ${ }^{20}$}

A calcite vein in a light-colored intrusive rock in the Cerro del Yeso, near San Javier in north-central Sinaloa, was explored in January 1944. The vein crops out for 90 meters and has a maximum width of 3 meters. It strikes nearly east. The best calcite obtained from some small pits along the vein was nearly opaque, badly fractured, and contained abundant twinning lamellae. There seems little chance. of finding any usable calcite along this vein.

\section{PITAYITA DISTRICT, SINALOA (27) ${ }^{21}$}

A calcite vein near Pitayita was explored during January 1944 by means of three small trenches. . . The deposit is reached from Badira-. guato, in north-central Sinaloa. The vein crops out in a light-colored: intrusive rock and is a little more than half a meter wide where ex-. plored. The best crystals obtained from the workings are pale yellow. and contain abundant twinning lamellae and cleavage fractures. It is questionable whether any usable calcite could possibly be obtained from this vein.

\section{LOS TERREROS DISTRICT, SINALOA $(28)^{22}$}

Massive veins of calcite occur in the Loma del Ermitaño, near Los Terreros in north-central Sinaloa. The area can be reached by truck from Badiraguato. The veins are in a light-colored intrusive rock,

${ }^{20}$ Described in a manuscript report by C. E. Pouliot, of the Foreign Economic Administration.

a1 Described in a manuscript report by C. E. Pouliot of the Foreign Economic Administration.

22 Described in a manuscript report by C. E. Pouliot of the Foreign Economic Administration. 
and the best calcite obtained from them is opaque and strongly twinned. Further exploration in the district is not likely to discover much better calcite.

\section{DISTRICT SOUTH OF ANTONIO AMARO, DURANGO (29)}

Two veins about 25 kilometers south of Antonio Amaro, in eastern Durango, were explored during the spring of 1944 . The deposits are about 6 kilometers beyond the end of the nearest road. They are in rhyolitic tuff near the contact of the tuff with some flows of basalt. One of the veins, explored by Jesús Martínez and Guadalupe García of Antonio Amaro, crops out for about 20 meters and varies in width from 2 to 20 centimeters. It strikes N. $50^{\circ} \mathrm{E}$. and dips $75^{\circ} \mathrm{SW}$. A pit 3 meters long and 2.5 meters deep exposes narrow cavities lined with thin long scalenohedral crystals too small to be of use; the largest crystals contain abundant twinning lamallae and fractures. Another vein about a kilometer northwest of this one, not examined by the writer, was described as being similar to it. There seems little chance of obtaining any usable calcite from these veins. Any further search should be limited preferably to the basalt.

\section{DISTRICT EAST OF ANTONIO AMARO, DURANGO (30)}

Veins in some hills about 7 kilometers northeast of the Dos de Abril Ranch, which is east of Antonio Amaro in eastern Durango, were explored by means of two or three small pits. The veins are in limestone of Cretaceous age. As the calcite is opaque, no usable material can be expected from this district.

\section{OCHOA DISTRICT, DURANGO (31)}

Small veins were explored at two or three places about a kilometer north of the town of Ochoa, in eastern Durango. The veins are in well-bedded calcareous sediments.: "Most of the calcite is opaque, and even the clearest is not clear enough for suboptical use. It is highly questionable whether any usable calcite can be found nearby. 


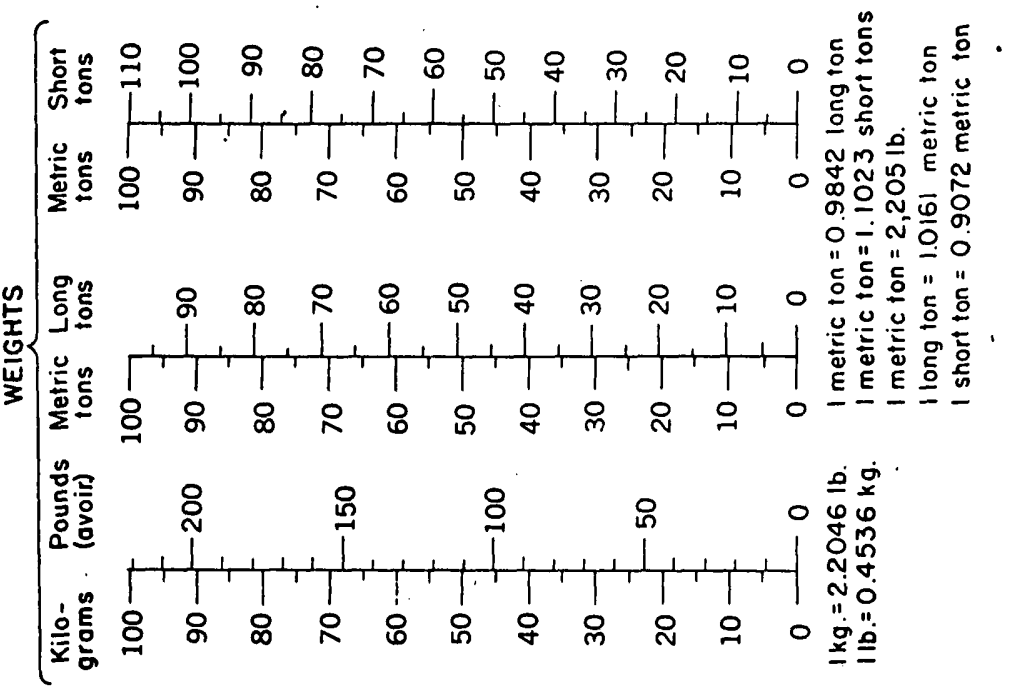

点

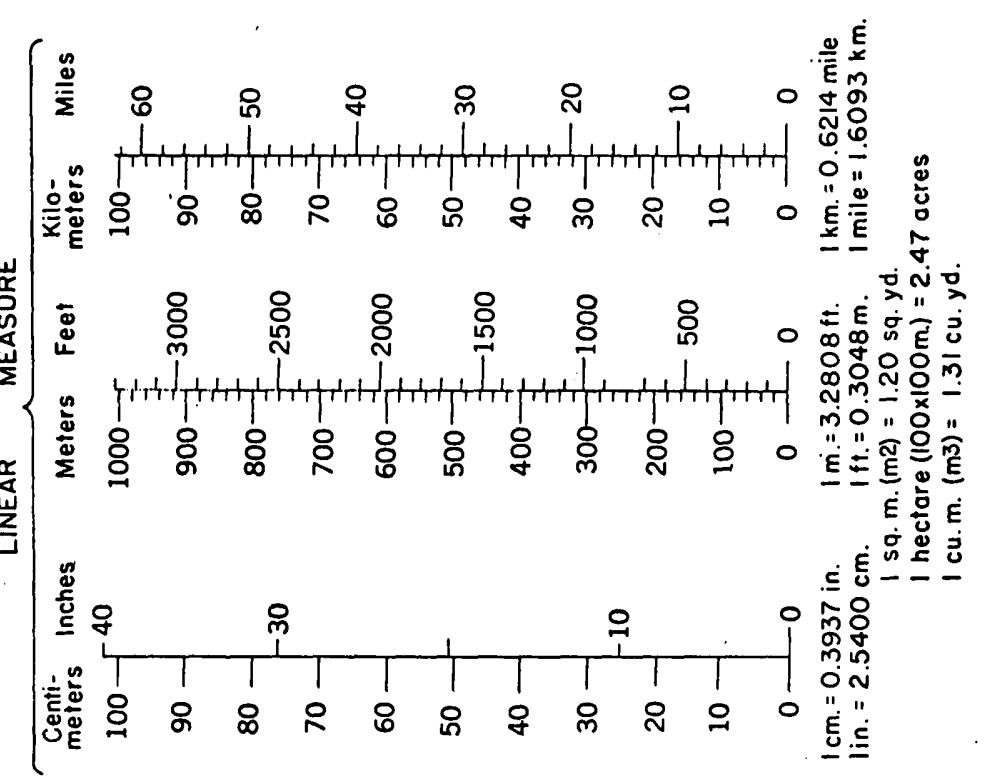

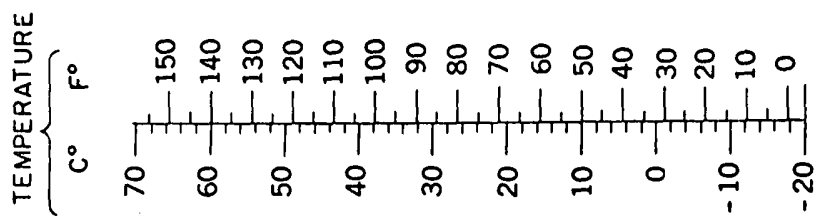





\section{INDEX}

Page

Abstract

$113-114$

Acknowledgments

$115-117$

Antonio A maro, deposits in district east of . - $\quad 176$

deposits in district south of.............. 176

Areponapuchic district, deposits in ........ 155-160

Arizpe district, deposits in ..................... 172

Bacadehuachic district, deposits in .. 162-164; pl. 24

Calcite, optical, consumption of .

136

optical, factors affecting quality of...... 141-145 geologic character of . ............... 137-139

marketing of . . ................. 137, 149-150

methods of mining and selecting .... 145-148

price of ............................. 137

production and reserves of.......... 150-152

recognition of defects in ............ 132-136

specifications of ................. 131-132, 133

structures favorable to occurrence

of .................. 140 141; pls. 24, 29

uses of .......................... 131

Calcite crystals, properties of ....... 120-130, 133, 134

varieties of . ........................ 119-120,

$121,122,125,126,127,133,134$

Chinipas district, deposits in

169

Chuhuichupa district, deposits in

173

Commercial deposits, shape and size of ...... $\quad 140$

Distribution of deposits

114-115; pl. 23

El Catiman deposit, description of ....... 150; pl. 27

El Caliche mine, description of . ............ 169-170

El Cristal mine, description of ............... 167-168

El Fuerte district, deposits in . .............. 175

E1 Murcielago district, deposits in . ........ 160-162;

pls. 28,31

El Parron district, deposits in .
Page

El Porvenir deposit, description of ......... 156-157;

pls. $3,24,25,26,27$

Esqueda, deposits in district east of . . ....... 172

Exploration and mining, history of ........ 117-119

Guasabas district, deposits in............... 173

La Aurora deposit, description of . . ....... 157-158;

pls. 26,27

La Esmeralda mine, description of. .. 170-171; pl. 32

La Fe mine, description of............... 153; pl. 30

La Flor de Esperanza deposit.... 158-159; pls. 27, 31

La Mula, deposits in district of.............. 174

La Perla vein, deposits along the . . ....... 159-160;

pls. 27,32

Los Terreros district, deposits in. ......... 175-176

Manuel Benavides, deposits in district east

of . . . 174-175

deposits in district south of .............. 174

Mapimi district, deposits in ............... 171-172

Metric equivalents, chart showing........... 177

Monterde district, deposits in . ............. 165-166

Ochoa district, deposits in .................. 176

Oputo district, deposits in................ 168-169

Pitayita district, deposit in................. 175

Pito Real district, deposits in ............... 164-165

Prospecting, suggestions for.................. 148

Sahuaripa district, deposits in............... 173

San Isidro district, deposits in............. 166-167

San Javier district, deposit in................ 175

Tarahuncachic district, deposits in.......... 173

Urique canyon, deposits in the

160 